OPEN ACCESS

Edited by: Mario Guagliano,

Politecnico di Milano, Italy

Reviewed by:

Walter Caseri

ETH Zürich, Switzerland

Jian Yang,

Wuyi University, China

*Correspondence:

M. I. Khan

gorikhan@kust.edu.pk

Specialty section

This article was submitted to Polymeric and Composite Materials,

a section of the journal

Frontiers in Materials

Received: 12 February 2019

Accepted: 09 July 2019

Published: 31 July 2019

Citation:

Gul S, Khan SB, Rehman IU, Khan MA and Khan MI (2019) A Comprehensive Review of Magnetic

Nanomaterials Modern Day

Theranostics. Front. Mater. 6:179.

doi: 10.3389/fmats.2019.00179

\section{A Comprehensive Review of Magnetic Nanomaterials Modern Day Theranostics}

\author{
Saima Gul ${ }^{1}$, Sher Bahadar Khan ${ }^{2}$, Inayat Ur Rehman ${ }^{3}$, Murad Ali Khan ${ }^{1}$ and M. I. Khan ${ }^{\text {* }}$ \\ ${ }^{1}$ Department of Chemistry, Kohat University of Science \& Technology, Kohat, Pakistan, ${ }^{2}$ Center of Excellence for Advanced \\ Materials Research (CEAMR), King Abdulaziz University, Jeddah, Saudi Arabia, ${ }^{3}$ Gandhara College of Pharmacy, Gandhara \\ University Peshawar, Peshawar, Pakistan
}

Substances at nanoscale, commonly known as "nanomaterials," have always grabbed the attention of researchers for hundreds of years. Among these different types of nanomaterials, magnetic nanomaterials have been the focus of considerable attention during the last two decades as evidenced by an unprecedented increase in the number of research papers focusing these materials. Iron oxide magnetic nanoparticles have occupied a vital position in imaging phenomena; as drug vehicles, controlled/sustained release phenomena and hyperthermia; atherosclerosis diagnosis; prostate cancer. In fact, these are wonderful "theranostic" agents with some under clinical trials for human use. In this review, we have attempted to highlight the advances taking place in the field of magnetic nanoparticles as theranostic agents. Extensive progress has been made in the two most important parameters, namely, control over the size and shape which decide the importance of iron oxide magnetic nanoparticles by developing suitable procedures like precipitation, co-precipitation, thermal decomposition, hydrothermal synthesis, microemulsion synthesis and plant mediated synthesis. After using a suitable synthetic route, workers encounter the most daunting task linked with the materials at nanoscale i.e., the protection against corrosion. Only properly protected iron oxide magnetic nanoparticles can be further connected to different functional systems to make building blocks for application in catalysis, biology and medicines. Finally, "theranostics" which is a combined application of imaging and drug delivery has been discussed. With all the potential uses, toxicity of the of iron oxide magnetic nanoparticles has been discussed.

Keywords: iron oxide magnetic nanoparticles, synthetic routes, drug delivery, imaging, theranostic, atherosclerosis

\section{INTRODUCTION}

Scientists, and materials scientists particularly, have shown remarkable interest in the properties of magnetic materials on the nanometer scale, while life scientists are also benefiting from nanomagnets (Buzug, 2010). Iron oxide magnetic nanoparticles are quite different from other nanomaterials as the fundamental properties of magnets are defined at the nanoscale and measurements can be made in the range of a micrometer to a few nanometers in size (Riaz et al., 2015; Monsalve et al., 2017). Iron oxide magnetic nanoparticles are one of the most promising 
substances in clinical diagnostic and therapeutic applications (theranostics) (Ho et al., 2011; Ahmed et al., 2012). Superparamagnetism displayed by iron oxide magnetic nanoparticles makes ferromagnets useful for application in biomedical sciences; briefly, when compared with other nanomaterials, these are usually coated with inorganic materials like silica, organic fatty acids phospholipids, and so on, and these can be directed to active site by controlling with external AC magnetic field making these attractive for biomedical applications (Figure 1) (Li et al., 2013).

Recently, substantial efforts have been made in the field of iron oxide magnetic nanoparticles to develop and understand their behavior and for improving their applicability (Bansal et al., 2017). Control over the synthetic procedures including surface functionalization is imperative as it leads to their unique properties, such as physicochemical, stability and biological fate. For application in pharmaceutical and biomedical purposes, iron oxide magnetic nanoparticles should possess smaller size (50-160 $\mathrm{nm})$ and high magnetization values (Mohammed et al., 2017). Surface coatings are meant to ensure stability and biocompatibility for specific localization at the target site (Figure 2) (Kandasamy, 2017).

Nevertheless, the intrinsic instability is an inevitable problem related with these particles when stored over certain periods of time; as these small particles tend to agglomerate and reduce the energy associated with high surface to volume ratio of the nanoparticles (Kovár et al., 2017). Uncapped magnetic iron oxide nanoparticles are highly reactive and prone to easy oxidation under ambient conditions damaging in magnet behavior and dispersion (Yu et al., 2014). For these reasons, it is critical to devise strategies to achieve stability of the naked magnetic iron oxide nanoparticles and degradation in the course and after the synthetic procedures. One approach is to coat the magnetic nanoparticles with layers of organic or inorganic stabilizing agents; the major advantage of this strategy is that the coating not only gives stability, but these can further be used for functionalization depending on the anticipated application (Tombácz et al., 2015). After surface functionalization, iron oxide magnetic nanoparticles are capable of use as catalysts and biomarkers etc. (Pang et al., 2016). The objective this review is to bring into focus the syntheses and wide-ranging applications of iron oxide magnetic nanoparticles.

\section{SYNTHESIS OF IRON OXIDE MAGNETIC NANOPARTICLES}

A huge number of research papers have appeared during the last several decades describing the synthesis of magnetic iron oxide nanoparticles with versatile compositions and phases.

Synthetic routes are selected to control shape, stability and dispersion trends of iron oxide magnetic nanoparticles (Figure 3). Excellent quality iron oxide magnetic nanoparticle can be synthesized by adopting versatile synthetic approaches include thermal decomposition, co-precipitation, micelle formation, hydrothermal and laser pyrolysis techniques. It was difficult for us to compile all this literature and we have attempted to present each synthetic approach by giving a few examples along with the corresponding formation mechanism (Ali et al., 2016; Martínez-Cabanas et al., 2016; Elrouby et al., 2017; Kandasamy, 2017; Lin et al., 2017; Liu et al., 2017; Rajiv et al., 2017; Sathya et al., 2017).

\section{Solution Precipitation}

To date, precipitation from homogeneous solutions is a classical in use for decades for the lab-scale preparation of iron oxide magnetic nanoparticles (Pang et al., 2016). Routinely, during a precipitation reaction, a precipitating agent is added to the aqueous solution of metal precursor generating an insoluble solid product and the major benefit is the higher yields of the products. Another advantage of homogeneous precipitation reaction is the uniformity of the particles, a process that depends largely on the separation, the nucleation and growth of the particles (Yang et al., 2014).

Overall, precipitation methods are simple and allow the preparation of magnetic iron oxide nanoparticles with rigorous size and shape control and these reactions are employed to obtain uniform size of the product. Nucleation must be avoided during the growth process for achieving the monodispersity of the iron oxide magnetic nanoparticles (Mahmed et al., 2011).

\section{Co-precipitation Methods}

Co-precipitation is perhaps a more suitable method to prepare magnetic iron oxide nanoparticles from aqueous solution containing $\mathrm{Fe}(\mathrm{II})$ and $\mathrm{Fe}(\mathrm{III})$ by adding a base under anaerobic condition at ambient or high temperatures (Lodhia et al., 2010). However, there are certain factors like the type of iron salts, $\mathrm{Fe}(\mathrm{II}): \mathrm{Fe}(\mathrm{III})$ ratio, temperature of the reaction, $\mathrm{pH}$ of the medium, volume and ionic strength of the solution that markedly affect size, shape and composition of the magnetic iron oxide nanoparticles (Surowiec et al., 2017). In the co-precipitation approach, once the synthetic conditions are met, the quality of the magnetic iron oxide nanoparticles is successfully reproducible. At laboratory conditions, nanoscale magnetite tend to decompose easily to maghemite when dissolved in an acidic solution which is a ferrimagnetic material; therefore, magnetite can be deliberately oxidized to maghemite. This can be achieved by dispersing magnetite in acidic medium followed by the addition of Fe(III) nitrate; thus, the product obtained furnished excellent chemical stability to basic as well as acidic conditions. Therefore, altering conditions of the aforesaid process is the key in controlling the dispersion behavior of magnetic iron oxide nanoparticles; the size and shape of the SPIONs can be successfully tailored by adjustment of $\mathrm{pH}$, ionic strength, temperature, nature of the salts used and concentration ratio of $\mathrm{Fe}^{\mathrm{II}} / \mathrm{Fe}^{\mathrm{III}}$. While addition of organic chelating agents or polymers surface complexing agents during the formation of magnetite can help to control the size of the nanoparticles (Mascolo et al., 2013).

Recently, monodispersed magnetic iron oxide nanoparticles of variable sizes have been reported by the use of the stabilizing agent polyvinylalcohols in chainlike clusters signifying the importance of appropriate surfactant for stability (Freitas et al., 2015). Organic stabilizing agents containing carboxylate and hydroxide anions have been the priority choices as they 


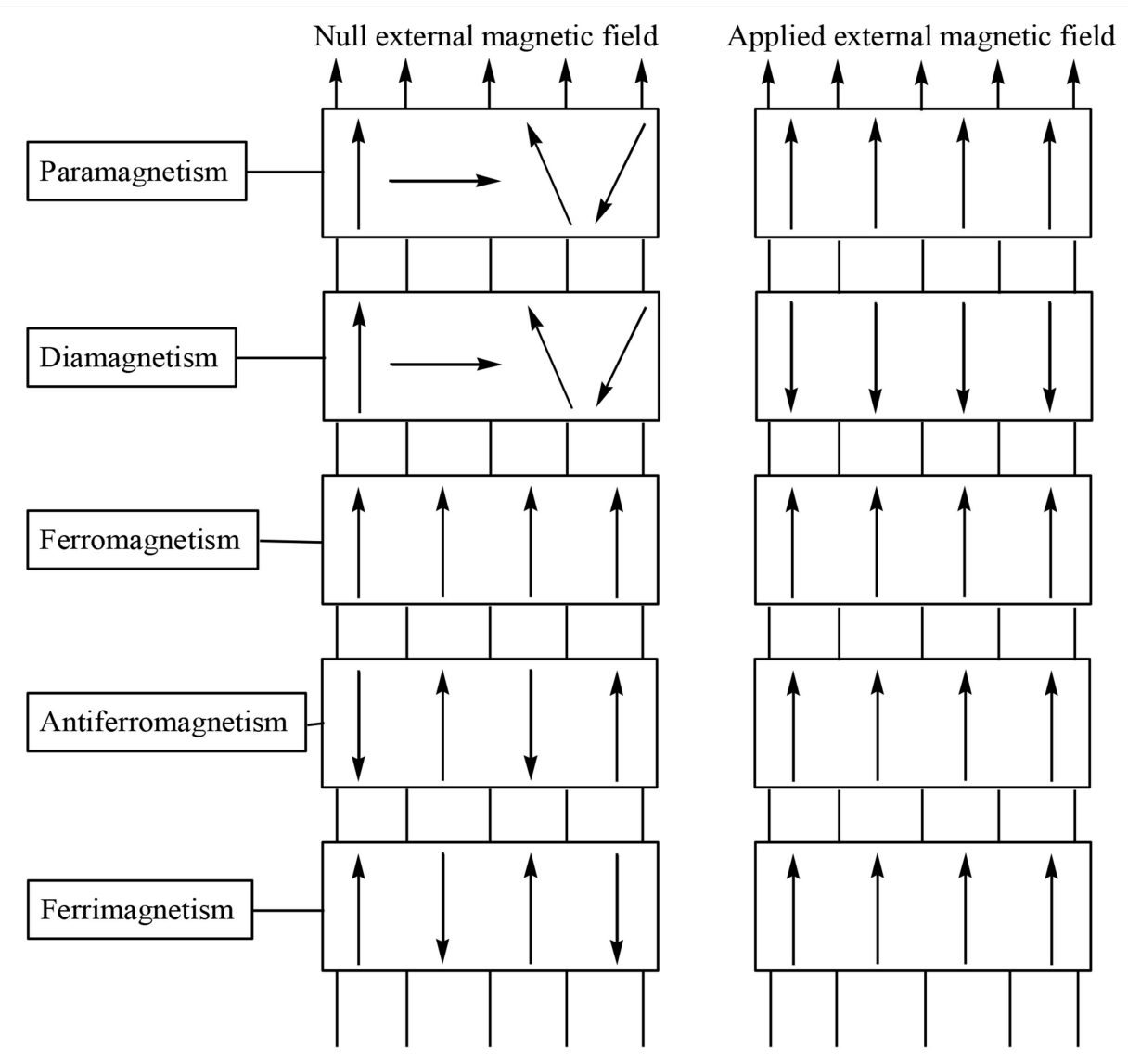

FIGURE 1 | Magnetism in the presence and absence of an external applied magnetic field.

form surface complexes by competing mechanisms ( $\mathrm{Lu}$ et al., 2007). First is the complex formation of metal ions which prevents nucleation; second is the adsorption of additives on nuclei thereby inhibiting particles' growth (Boyer et al., 2010). All these facts make co-precipitation as the most widely used excellent synthetic route to obtain magnetic iron oxide nanoparticles.

\section{Thermal Decomposition Approach}

In this approach, generally organometallics compounds are decomposed; organometallic precursors are decomposed in organic solvents using surfactants as capping agents under anaerobic conditions and it is a very diverse approach for the synthesis of magnetic iron oxide nanoparticles (Laurent et al., 2008). Thermal decomposition helps achieve control of the size and shape and dispersion behaviors of the nanomaterials; however, safety issues are associated at higher temperatures and pressure of organic liquids and vapor phases used during the reactions conducted in the absence of air (Figure 4) (Dong et al., 2015). But one question has always arisen that, If the reaction is carried out in the absence of oxygen, how can metal oxide nanoparticles be formed successfully and reproducibly? The answer to this is example of iron oxide as in the first step ferrous hydroxide is formed, which is then oxidized to iron oxide by the protons of water to different types of iron oxides.

Reaction conditions, for instance temperature, duration of the reaction and the aging may also be vital for controlling size and morphology (Patsula et al., 2016). Annealing temperature is another factor which allows for the control of size and size distribution, namely the dispersion of the synthesized iron oxide magnetic nanoparticles, their structural motifs and magnetic properties. Monodispersed iron oxide magnetic nanoparticles in the size range of $6-20 \mathrm{~nm}$ were reported prepared by the polymer-catalyzed decomposition of reaction of $\mathrm{Fe}(\mathrm{CO})_{5}$ (Smith and Wychick, 1980; Huber, 2005). Literature also reports very precise control of the size of iron oxide magnetic nanoparticles; this was successfully achieved by thermally decomposing larger concentrations of expensive and toxic precursors as well as surfactants in organic medium. Precursors containing zerovalent metal like $\mathrm{Fe}(\mathrm{CO})_{5}$, initially lead to metallic nanoparticles followed by oxidation yielded high quality monodisperse iron oxide magnetic nanoparticles (Effenberger et al., 2017). In contrast, iron(III) acetylacetonate when treated under identical conditions decomposed to cationic metal centers (Hufschmid et al., 2015). Another drawback associated with this method is the solubility of magnetic nanoparticles in organic solvents; this restricts their usage in biology and medicine. Even surface 
A

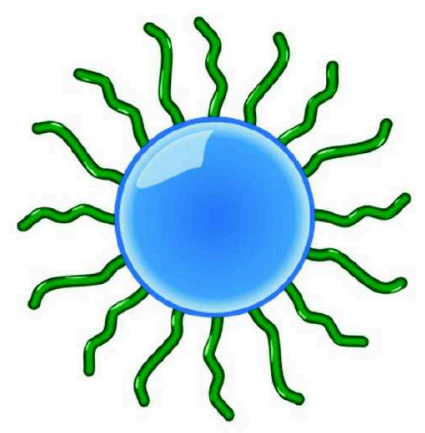

D

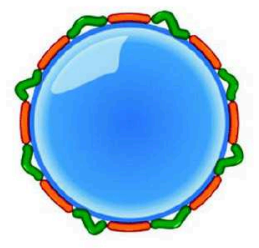

B

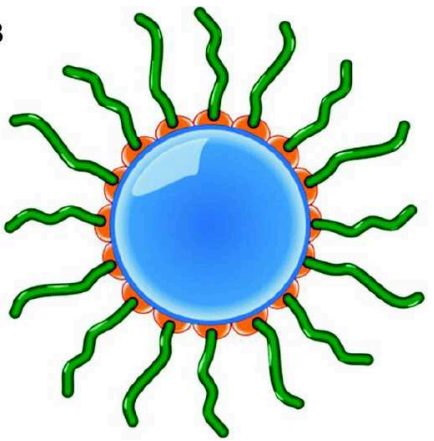

E

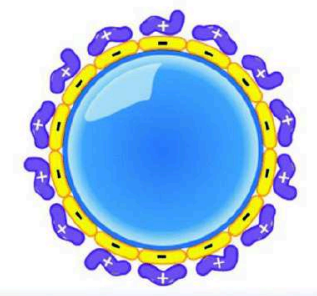

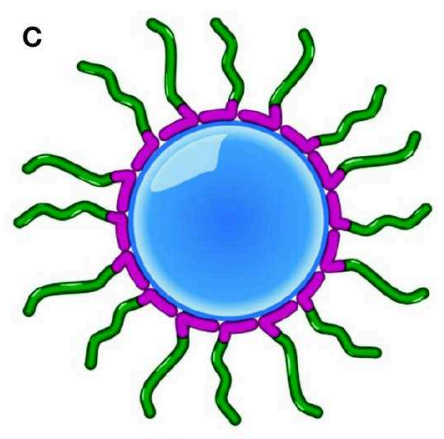

$\mathbf{F}$

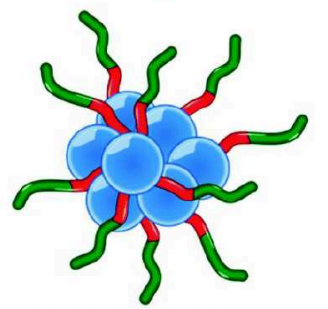

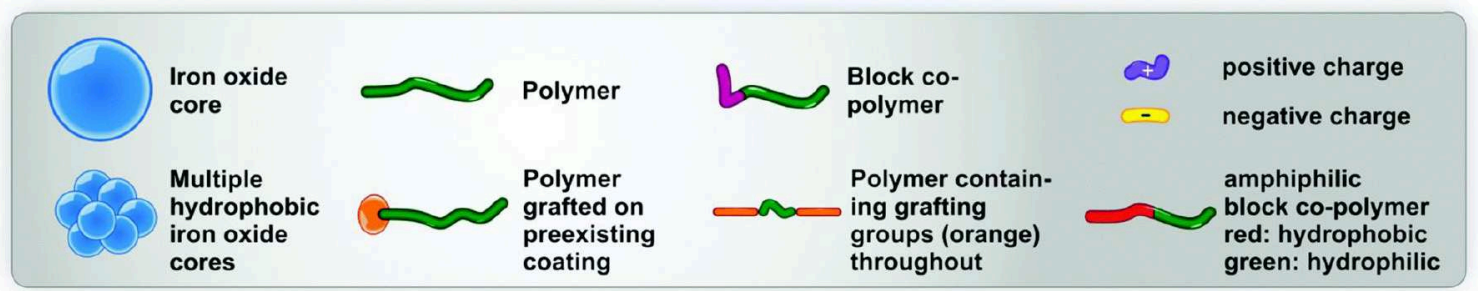

FIGURE 2 | Stabilization of iron oxide nanoparticles; (A) polymer end bearing functional group (B) polymer-grafted (C) di-block copolymer with grafting groups (D) wrapping conformation of the polymer (E) coatings with opposite charges (F) amphiphilic polymers [adapted and modified from Barrow et al. (2015) and Habibi et al. (2017)].
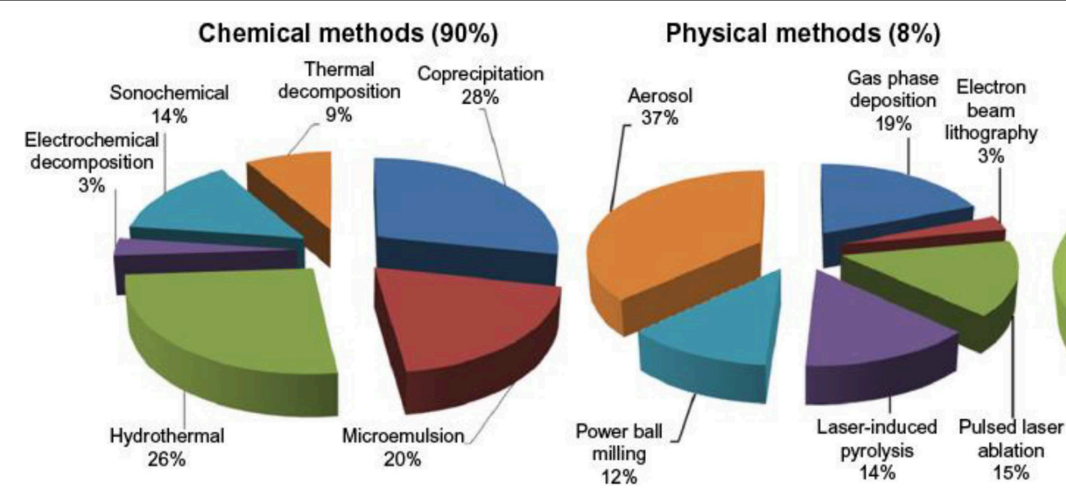

\section{Biological methods (2\%)}

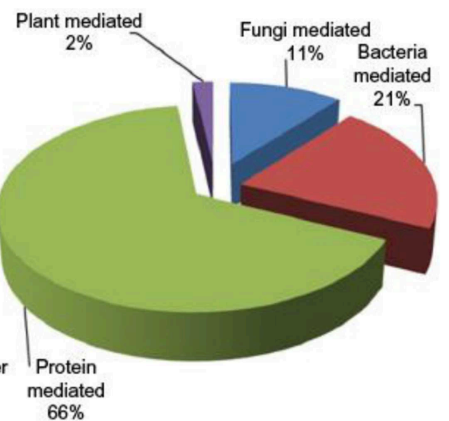

FIGURE 3 | Comparative presentation of the synthesis of iron oxide magnetic nanoparticles by three different routes [adapted and modified from Ali et al. (2016)].

modification has no significant impact on the solubility of nanoparticles which are generally only dissolved in non-polar solvents (Dong et al., 2015).

\section{Polyol Method}

Polyol method is a liquid-phase synthetic approach for magnetic iron oxide nanoparticles in multivalent alcohols under higher boiling conditions (Hufschmid et al., 2015). Ethylene glycol is the simplest representative of the polyol family and, based on this, polyols comprise of a series of glycols diethylene glycol, triethylene glycol, tetraethylene glycol up to polyethylene glycol (Figure 5) (Deshmukh and Niederberger, 2017). Polyethylene glycol is available in a wide range of molecular weights and the respective product may contain up to 100,000 ethylene groups; other examples of this family are propanediol, butanediol, pentanediol, glycerol, and pentaerythritol and certain 


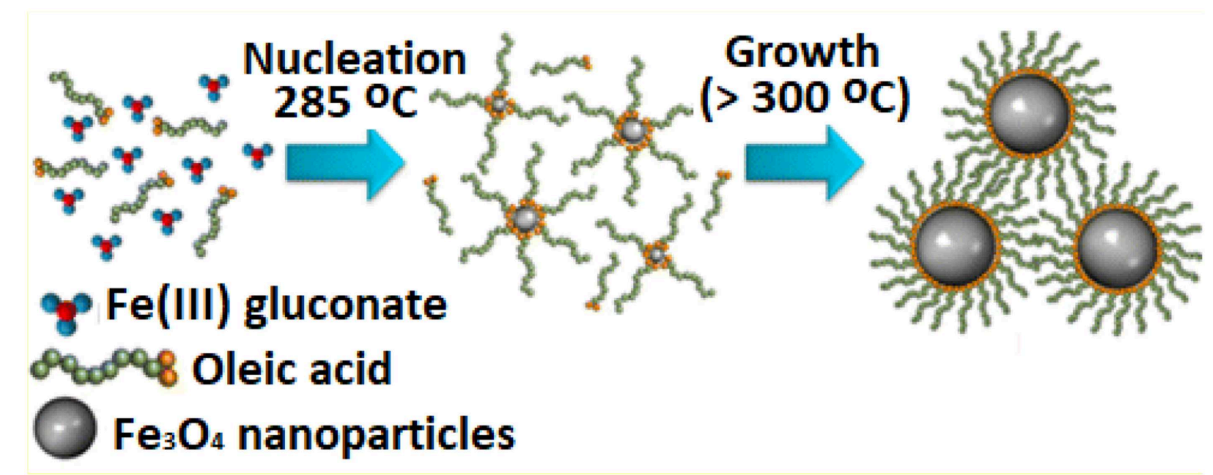

FIGURE 4 | Thermal decomposition of iron(III) glucuronate to synthesize superparamagnetic $\mathrm{Fe}_{3} \mathrm{O}_{4}$ nanoparticles [adapted and modified from Patsula et al. (2016)].

carbohydrates. Polyol is a very promising approach to synthesize uniform magnetic iron oxide nanoparticles, having the potential use in magnetic resonance imaging. The reason for the success of the polyol method is that all these polyols are watercomparable and chelation; polyols instantaneously coordinate to the nuclei formed and this allow excellent control of particle size, dispersity and particle distribution. Post synthesis treatment for the removal of polyols can be achieved easily by repeated washing with simple water, coordination exchangers like carboxylates, amines etc. and thermal annealing (Watt et al., 2017). Particle size increases with the increasing precursor's concentration and water; particle size can be limited to minimum depending on the solubility of the product in the polyol. A bigger advantage of the polyol method is the production of highly crystalline oxide nanoparticles based on elevation of the temperature of reaction medium; this rules out any post-sintering treatment of the product (Yang et al., 2014). Apart from conventional heating, other sources like microwaves and ultrasonic waves have been successfully applied (Hemery et al., 2017). The synthesis of metal oxides can be restricted by the reducing action of polyols yielding elemental metals, and it is also possible by adjusting the reaction temperature (Wee et al., 2017).

\section{Microemulsion Synthesis}

When two immiscible solvents are mixed together, a thermodynamically stable isotropic dispersion is formed which is defined as microemulsion with the presence of an interfacial layer of surfactant's molecules (de Toledo et al., 2018). Surfactants molecules generally bearing hydrophilic heads soluble in water and hydrophobic tails soluble in oil phase form a monolayer at the interface of the two immiscible liquids (wateroil) (Williams et al., 2016). Surfactant is an amphiphilic molecule playing a role to lower the water-oil interfacial tension to give a transparent solution. Microemulsion technique has several advantages when compared with other synthetic strategies. For example, with the use of simple equipment, a great variety of nanomaterials can be synthesized with excellent control over size, shape and composition, desired crystalline structure and high specific surface area, simple synthetic conditions at ambient/near ambient temperatures and pressures (Zhao et al., 2016). Microemulsions of water-in-oil are formed when microdroplets (up to $50 \mathrm{~nm}$ ) of water surrounded by a monolayer of surfactant molecules are dispersed in continuous hydrocarbon phase (Drozdov et al., 2016). If two identical water-in-oil microemulsions containing the desired reagents are mixed, the microdroplets formed will experience continuous collisions, coalesce and break again and again leading to the appearance of precipitate inside the micelles. After completion of the reaction, acetone or ethylalcohol are added for extracting the precipitate via filtration or by centrifugation.

Microemulsions are termed as "nanoreactors" to produce nanoparticles, mixed metal-iron oxide magnetic $\left(\mathrm{MFe}_{2} \mathrm{O}_{4}, \mathrm{M}\right.$ : first row transition metals) nanoparticles are one of the most interesting materials used for electronic applications (Gutiérrez et al., 2015). $\mathrm{MnFe}_{2} \mathrm{O}_{4}$ nanoparticles in the range $4-15 \mathrm{~nm}$ are successfully synthesized through water-toluene inverse micelles with sodium dodecylbenzenesulfonate surfactant, aqueous solutions of $\mathrm{Mn}\left(\mathrm{NO}_{3}\right)_{2}$ and $\mathrm{Fe}\left(\mathrm{NO}_{3}\right)_{3}$ as starting precursors. The microemulsion method used for the magnetic nanoparticles yielded spheroids with a rectangular cross section or as tube (Hasany et al., 2013). A wide range of magnetic nanomaterials have been synthesized using the microemulsion method with good control and the sizes, as well as shapes, usually varied over a wider range. In the microemulsion technique, large quantities of solvents are used to produce considerable amounts of nanomaterial; based on this, it's categorized as a very efficient procedure and relatively difficult to be applied at large scale (Figure 6) (Kumar et al., 2013; Williams et al., 2016).

\section{Hydrothermal Route}

Hydrothermal or solvothermal route is one of the most successful methods to prepare magnetic nanoparticles and ultrafine powders (Malo de Molina et al., 2016). By using this technique, crystals of different materials have been grown satisfactorily. Generally, hydrothermal synthesis accompanies higher temperatures $\left(125-250^{\circ} \mathrm{C}\right)$ at very high pressures $(0.3-$ $4 \mathrm{MPa}$ ) (Cai et al., 2013; Madadlou et al., 2014; Yelenich et al., 2015). Powdery iron oxide magnetic nanoparticles with $40 \mathrm{~nm}$ diameter have been reported using hydrothermal route $\left(140^{\circ} \mathrm{C}\right)$ 


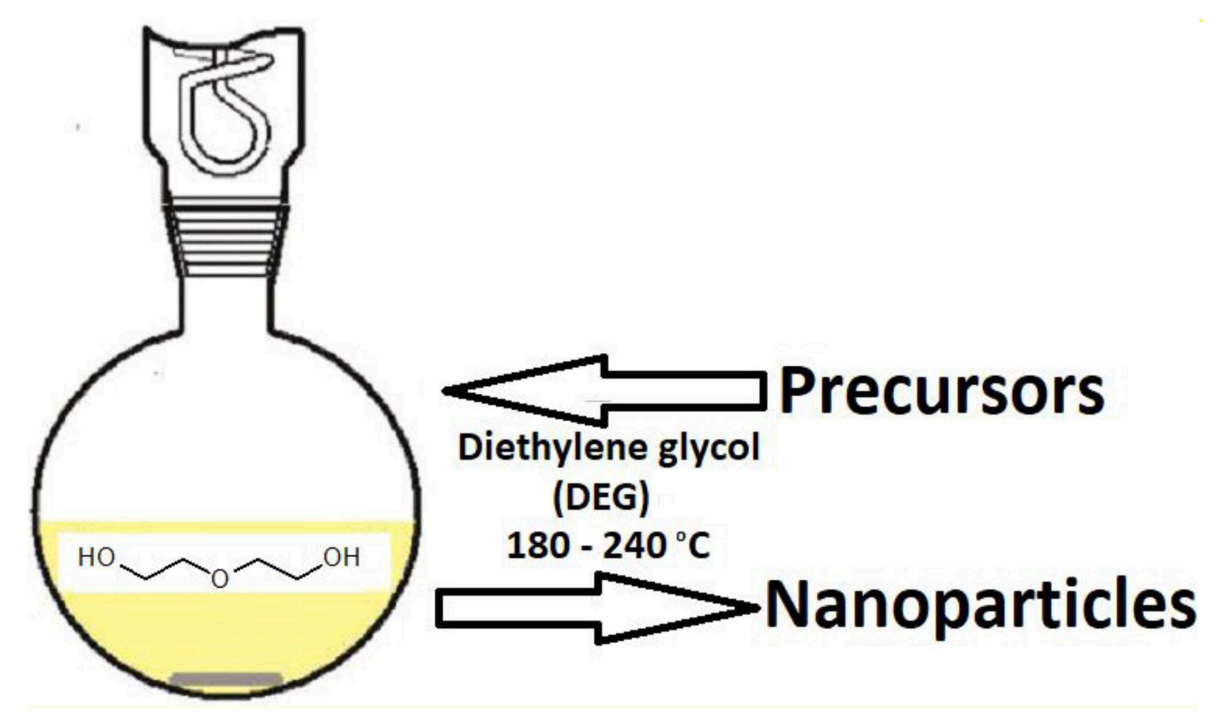

FIGURE 5 | Polyol route for the synthesis of nanoparticles [adapted and modified from Dong et al. (2015)].

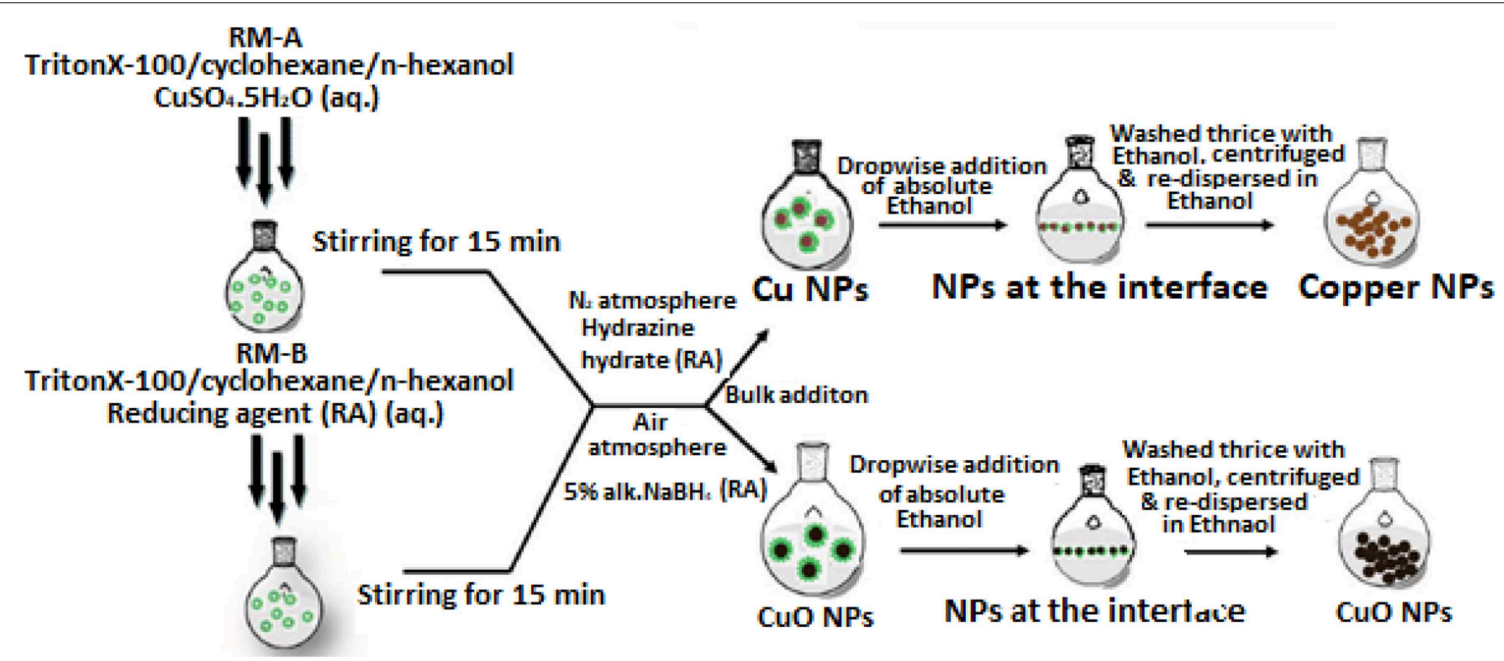

FIGURE 6 | Reverse phase microemulsion route for size-controlled synthesis of Cu and CuO nanoparticles [adapted and modified from Kumar et al. (2013) and Williams et al. (2016)].

and a saturation magnetization of 85.8 emu. $\mathrm{g}^{-1}$, which is far lower than that of the bulk iron oxide.

Precursors' concentration controls the size and size distribution; however, the duration of the reaction had affected the average particle size more significantly; monodisperse particles were obtained at shorter reaction times (Guo et al., 2013). An increase in the precursors' concentration with the rest of the variables kept constant lead to spherical particles (15.6-4 nm) (Naghibi et al., 2014). A major drawback of the hydrothermal route is the slowness of kinetics at any given temperature; but this problem can be addressed using microwaves which can increase the kinetics of crystallization. A reaction mixture containing ethylene glycol, iron(III) chloride, sodium acetate and polyethylene glycol sealed inside a stainless-steel autoclave (Teflon-lined) was and heated at $200^{\circ} \mathrm{C}$ for 8-72 h, yielded monodisperse spheres in the range of 200$800 \mathrm{~nm}$. The mechanism is not yet clear, and the multicomponent approach seemed to be powerful in directing the formation of the desired materials.

\section{Biological Synthesis}

The introduction of Green Chemistry in nanotechnology has grabbed a great deal of attention from workers around the globe (Maryanti et al., 2014). The green chemistry approach includes chemical manipulations with the aim to either decrease or eliminate toxic materials dumped into the environment (Tadic et al., 2014; Nassar et al., 2016). Biological synthesis of metallic nanomaterials by plants resources is 
currently under development and one of the most researched areas under investigation. Plant-mediated syntheses of metallic nanomaterials is the most modern option for researchers, carried out by using various parts of plants including tissue, extracts, exudates and other parts of the living plants. Green methods that are environmentally-friendly, safe and non-toxic for the development of reliable and eco-friendly methods to produce nanomaterials are of great importance in biomedical applications.

Biological resources including microbes, enzymes, fungi and plant extracts have been utilized as eco-friendly alternates for the synthesis of nanoparticles (Shah et al., 2015; Dhal et al., 2017). In some papers, plants and/or their parts proved to be beneficial over the other biological processes like microbial or enzymatic resources by elaborating work to maintain microbial culture. Plants are green resources for the biological synthesis of nanoparticles containing reducing agents for instance citric acid, ascorbic acid, flavones, crude enzymes like dehydrogenases, reductases and extracellular electron shuttles, which plays a key role in the biological synthesis of nanoparticles (Figure 7) (Bai et al., 2009; Makarov et al., 2014; Baranwal et al., 2016).

Carob leaf extract has been successfully employed as a rapid, non-toxic, facile and green resource for preparation of iron oxide magnetic nanoparticles in a single step reaction using Fe(III): Fe(II) and sodium hydroxide solutions (Baxter-Plant et al., 2003). The reaction occurred at a relatively low temperature range in a single-vessel reaction with an average diameter of the monodispersed nanoparticles $(4-8 \mathrm{~nm})$ coated with carboxylic groups of respective amide-I and II chain of the proteins present in the extract (Rai et al., 2015).

As the biological synthesis of nanoparticles is a comparatively newer approach and is developing, these are certain disadvantages associated with it, for example, plants produce low quantities of secreted proteins which lead to a decreased rate of synthesis, creating the following implications: culturing microorganisms which takes more time; the prime objective of the synthesis of nanoparticles regarding control over size, shape and crystallinity is only achieved with difficultly; and most importantly is the dispersity of the nanoparticles, which are preferably monodispersed. Another disadvantage is that all the plants are not capable of being put to use for the synthesis of nanoparticles. The researchers are still working on the mechanisms of metal ion uptake and biological reduction by green approach.

\section{DRUG DELIVERY}

About 40 years ago, the concept of "magnetic drug delivery" was introduced as a very promising application of magnetic nanomaterials (Iravani, 2011). The concept of magnetic targeting starts with attaching drug molecules to magnetic nanomaterials followed by the injection and guidance of these particles to a site of action under the influence of localized magnetic field-gradients and holding there at site till the completion of therapy and final removal (Awwad et al., 2013). Literature reveals six types of magnetic materials, i.e., diamagnetic, paramagnetic, ferromagnetic, superparamagnetic, ferromagnetic and antiferromagnetic (Njagi et al., 2010). When the external field is removed, paramagnetic substances lose magnetic momentum and superparamagnetic materials become non-magnetic, but if an external field is placed, these develop a mean magnetic momentum. Magnetic nanoparticles can carry large doses of drugs to achieve high local concentration, avoiding toxic and other adverse side effects arising due to high drug doses in other parts of the organism (Langer, 1990). In vivo studies proved that actual clinical trials are a challenging task due to size control, stability, biocompatibility and coating-layer for drug binding and other physiological parameters.

The objective of developing and/or improving drug delivery systems is to position medications to target parts of the subject's body through a medium that can control the therapy's administration by means of a physiological or chemical trigger (Mody et al., 2014). Polymeric microspheres, micelles and hydrogels proved to be effective in enhancing drug target specificity, systemic drug toxicity lowering, improved treatment absorption rate and protection of pharmaceuticals against biochemical degradation (Bucak et al., 2012; Kharissova et al., 2013; Kharisov et al., 2014; Hola et al., 2015; Jiles, 2015; Anselmo and Mitragotri, 2017; Seeli and Prabaharan, 2017). In addition to these, biodegradable polymer and dendrimers based experimental drug delivery systems displayed exciting signs of promise (Figure 8).

Dendrimers, due to their size and structure, are suitable carriers and these can be easily processed to good biocompatibility and biodegradation, but these are poor coating materials magnetic nanoparticles ( $Y u$ et al., 2017). Suitable materials may be nanoparticles, emulsions, micelles and dendrimers etc.; a typical drug delivery process includes the loading of drugs in biocompatible carrier materials, transferred to bodies for cancer treatment. Biocompatibility, subcellular size and targeting action make nanoparticles excellent carrier materials and several nanosized materials have shown interesting potential for drug delivery; this potential stems from their intrinsic magnetic properties, such as room temperature superparamagnetism, magnetization and high magnetic susceptibility (Figure 9).

Surface functionalization by chemical as well as biological means improve stability and biocompatibility of the magnetic nanoparticles. The most interesting aspect of magnetic nanoparticles in drug delivery is the controlled delivery of drugs to target site under external magnetic fields. Magnetic driving of drugs to the target area is based on the binding of drugs to ferrofluid and desorption from the ferrofluid after reaching the target site by external magnetic field. Still, a lot of work is needed to be done, as successful drug delivery is affected by different factors, for example $\mathrm{pH}$, temperature, osmolality, and so on (Veiseh et al., 2010). The strength of the external applied magnetic field may hamper the magnetic drug delivery process as living cells withstand to a certain extent. The responsive nature of the magnetic nanoparticles carriers to external magnetic fields is due to the presence of incorporated magnetic materials, for example magnetite and some other transition metals and mix-metals (Figure 10). 


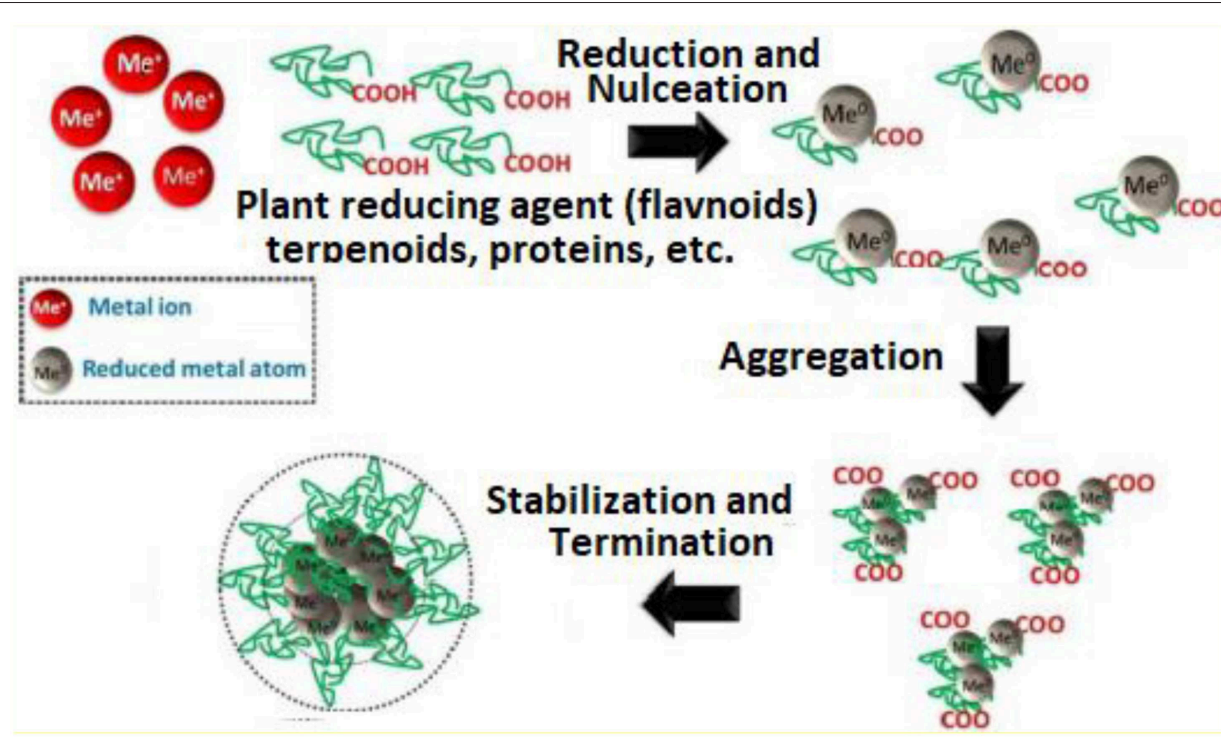

FIGURE 7 | Plant-mediated synthesis of metallic nanomaterials showing reduction as well as stabilization by secondary metabolites present in plant extracts for numerous applications in clinical research [adapted and modified from Makarov et al. (2014) and Baranwal et al. (2016)].

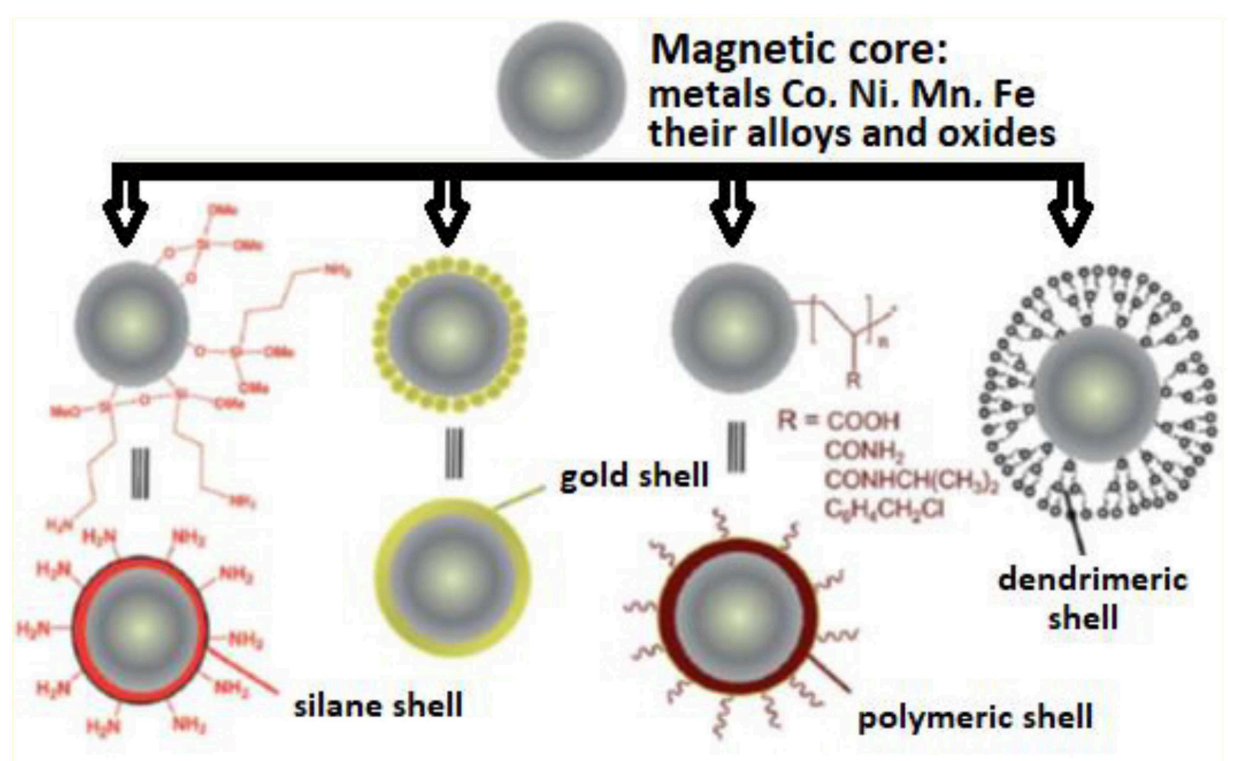

FIGURE 8 | Transition metal/metal oxides magnetic core-shell nanoparticles [adapted and modified from Kharissova et al. (2013)].

While designing a magnetic targeted drug delivery system, certain factors must be borne in mind like strength of the applied magnetic field and geometry. There are some other factors like magnetic properties and particles size, magnetic field strength, drug loading capacity, remoteness of the target site and blood flow rate. The aim of the magnetically targeted drug delivery system is to carry the drug to the site of action at a rate needed by the body during the treatment time (Funke and Szeri, 2017).

\section{IMAGING}

The most advanced application of nanoscale materials toward human health is the application of iron oxide magnetic nanoparticles-based formulations as a contrasting agent in magnetic resonance imaging (Fish et al., 2017). The past 50 years have seen remarkable improvements in diagnostic imaging procedures; for example in tumor diagnoses, damaged tissues and neurological disorders. Among various diagnostic imaging 

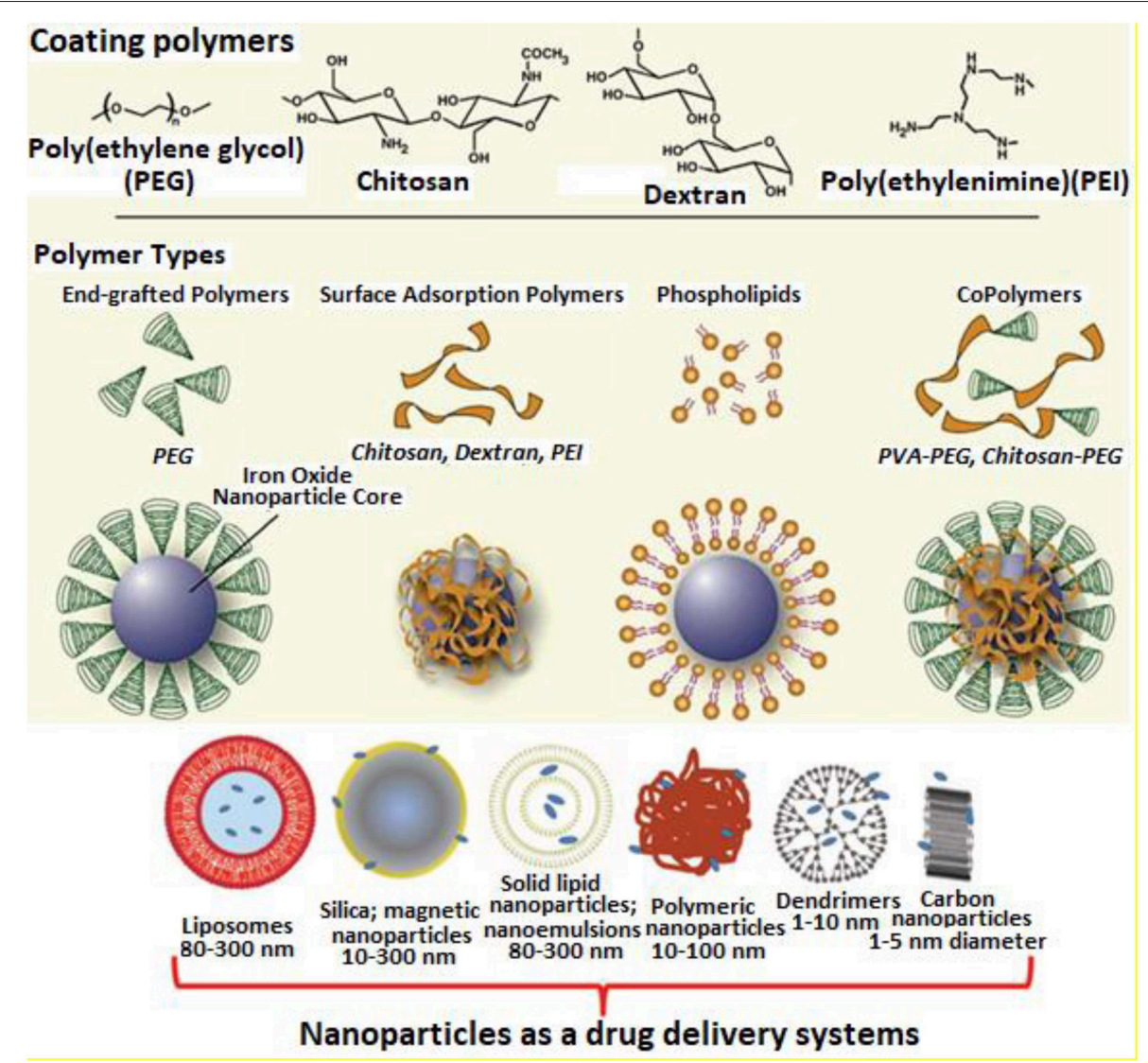

FIGURE 9 | Novel drug-carrier systems depicting different types of coating polymers and copolymers [adapted and modified from Veiseh et al. (2010)].

techniques, Magnetic Resonance Imaging abbreviated as MRI is an established tool in biomedical applications; exhibit stronger contrast of tissues makes it a favorable diagnostic test in medicine. In other diagnostic techniques like X-ray, the contrast quality is hindered leading to the misdiagnosis of several medical conditions. Looking at the superior contrast properties of MRIs, developments are needed and are made possible using a special medium called contrast agent (Hyeon et al., 2016). Contrast agent consists of a metal-based core with an external coating of a biocompatible material; the contrast agent intensifies the contrast of images obtained from MRI for accurate diagnoses. MRI equipment exerts a strong magnetic field within the CAs as well as other magnetic particles of biological significance respond (Hachani et al., 2016). MRI contrasting agents are classified into five categories as: $\mathrm{T}_{1}, \mathrm{~T}_{2} / \mathrm{T}_{2}^{*}$, CEST, ${ }^{19} \mathrm{~F}$-based and hyperpolarized agents ( $T_{1}$ and $T_{2}$ are relaxation rates) (Sood et al., 2017).

$\mathrm{T} 1$ agents include paramagnetic $\mathrm{Gd} \mathrm{d}^{\mathrm{III}}$ or $\mathrm{Mn}^{\mathrm{II}}$ complexes capable of enhancing the magnetic resonance water signal known as "signal brightening." The benefits of using $\mathrm{T}_{1}$ contrasting agents relies on the high versatility of the interesting contrast mechanism that is dependent on their structures and biological aspects; for example, the use of paramagnetic complexes to see the delivery as well as the drug release from liposomes (Xiao et al., 2016). However, these systems have got limited sensitivity based on the local concentration. To tackle this problem, scientists proposed the use of nanoscale materials which will aggravate numerous contrasting unit's necessary to detect a $\mathrm{T}_{1}$ contrast. $\mathrm{T}_{1} / \mathrm{T}_{2}^{*}$ contrasting agents are mostly superparamagnetic iron oxide nanoparticles capable of shortening $\mathrm{T}_{1} / \mathrm{T}_{2}^{*}$ of water protons than $\mathrm{T}_{1}$ signal; in fact, they darken the MRI due to signal loss. $\mathrm{T}_{1} / \mathrm{T}_{2}^{*}$ show higher intrinsic sensitivity than $\mathrm{T}_{1}$ contrasting agents which make them highly helpful in cellular imaging; this signal loss is undesirable as in the case of intrinsically low signal locations such as the lungs, while $r_{2}$ is the relaxivity of the CA as a function of effect of concentration of the solution on the relaxation rates reflects the (Figure 11). This can be explained by classical outer-sphere relaxation theory that, with the increase in particle size, the relaxavity ratio $\left(r_{1} / r_{2}\right)$ increases while decrease in particle's size lead to better T1-shortening (Taboada et al., 2007; Xiao et al., 2016).

CEST (Chemical Exchange Saturation Transfer) is the future of MRI contrasting agents; the principal governing CEST imaging is that these agents generate MRI contrast signals through chemical exchange of saturated protons from donor (CEST) to acceptor (water) (Taboada et al., 2007; Xiao et al., 2016). The uniqueness of using CEST agents is that the contrasting signal can be detected by irradiating with the characteristic NMR resonance of the donor. The ${ }^{19} \mathrm{~F}$ nucleus is the most sensitive 


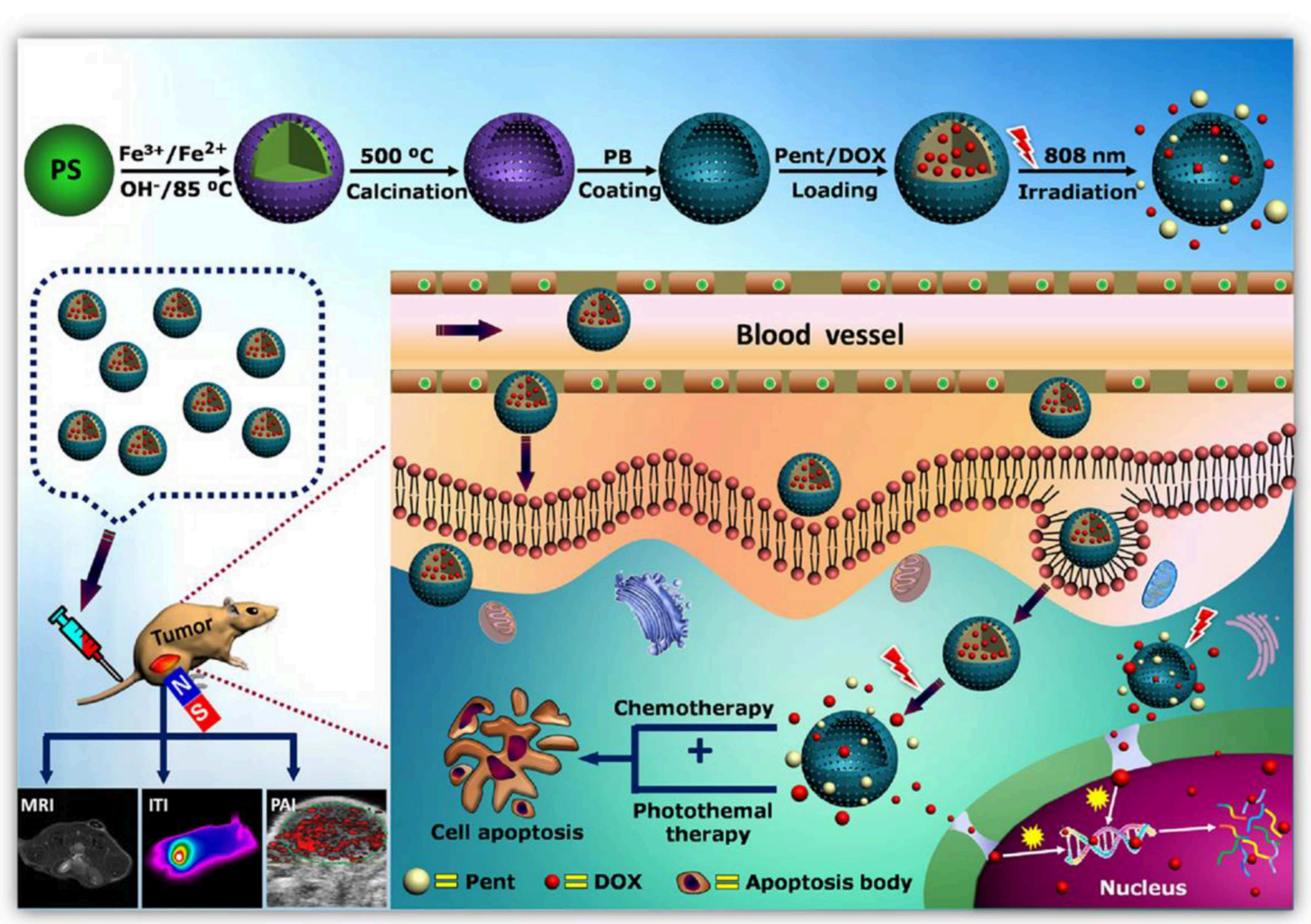

FIGURE 10 | Controlled delivery of anti-tumor drug with a new design incorporating a phase-change material in magnetic nanoparticles allowing chemo-photothermal combined tumor therapy with multimodal tumor imaging [adapted and modified from: http://www.advancedsciencenews.com/pent-drug-delivery-tumor-therapytrimodal-imaging (accessed on July 07, 2018, 2200 PST)].

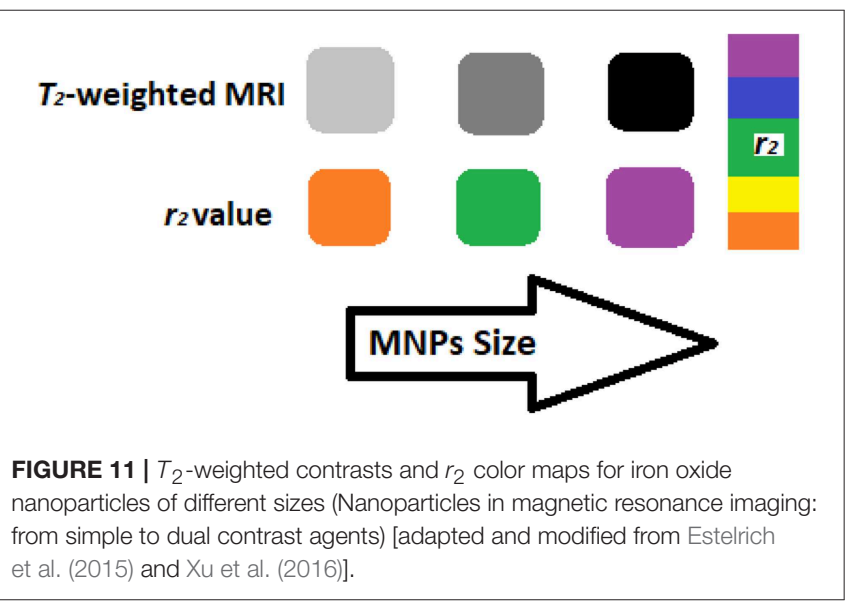

spin after proton so needs no enrichment, bearing similar detection sensitivity to CEST. Fluorinated agents are preferred over other media agents, due to possible correlation of signal to agent concentration (Bünzli, 2016). Hyper polarized agents are the most sensitive media contrasting agents using polarization techniques which dramatically increase the population difference between the spin energy levels. These have got limited use because of the signal loss over time.
Before extending our discussion about nanoscale magnetic materials as contrasting media, some in vivo considerations must be discussed like toxicity, size and shape, and charge. Iron oxide magnetic nanoparticles are regarded as harmless for in vivo applications; based on iron's concentration inside the human body. Iron becomes toxic at a concentration level of $60 \mathrm{mg} / \mathrm{kg}$; iron oxide magnetic nanoparticles have been used as contrasting agents for more than two decades in clinics are below $1 \mathrm{mg} / \mathrm{kg}$. However, iron oxide magnetic nanoparticles have been reported to have adverse effects on cell cultures based on the proposal that the internalization of nanoparticles alters the fate of the cells. Iron oxide magnetic nanoparticles consist of two components, namely magnetic core and organic coatings, and the role of the contribution of either of these is difficult to assess. Moreover, the toxicity of iron oxide magnetic nanoparticles is not dependent only on organic coating but cell type as well. Iron oxide magnetic nanoparticles can induce oxidative stress by disturbing oxidant/antioxidant balance.

Based on the size, charge and shape, the potential toxicity of iron oxide magnetic nanoparticles has been closely related to two factors, their size and charge, while less is reported about the relation to shape. Sizes between 10 and $100 \mathrm{~nm}$ have longer halflifes in the blood and are small enough to go through capillaries; these considerations are to be kept in mind while cancer imaging is under discussion relevant to size (Estelrich et al., 2015; Xu et al., 
2016). Organic polymers of molecular weights above $50 \mathrm{kDa}$ has been found to have an effective blood half-life of $6 \mathrm{~h}$. The in vivo effect of shape on the toxic behavior of iron oxide magnetic nanoparticles is difficult to assess because of the difficulty in the preparation of comparable samples of nanoparticles with different shapes (McMahon and Bulte, 2018).

\section{THERANOSTICS}

Theranostic is the seamless integration of therapy and diagnosis into one step; it is perhaps one of the trend setters in modern day research. The pivotal idea behind theranostic is that nanoparticles are unique in nature, i.e., these are capable of imaging and treating a lesion simultaneously (Khandhar et al., 2017). A careful survey of the literature revealed it was 2006 when this term was coined for the first time in scientific literature; theranostics was described as "Future nanotechnology developments will most likely include the capability of designing and fabricating multifunctional nanoparticles to combine imaging and therapeutic capabilities ("theranostics")" (Sun et al., 2016). In this regard, iron oxide magnetic nanoparticles have attracted interest due to their unique magnetic properties which make these excellent MRI contrasting agents and effective cytotoxic agents against tumors.

The use of nanoparticles allows imaging and treatment to be achieved simultaneously, in addition it also assists multiple treatment modalities in combination. This multi-modal approach was observed during the use of cisplatin-bonded gold nanospheres to administer chemo-radiotherapy in GBM cell models, leading to apoptic cell death after the intracellular uptake (Li et al., 2017). During the experiment, it was observed that due exposure to radiation in either of the metals started functioning as high atomic number radiosensitising agents and initiated the release of photoelectrons and Auger electrons. Radiosensitisation of the nanoparticle's formulations enhanced the in vitro cytotoxic effects of chemo- and radiotherapy and contributed to the photoablation of tumor cells (Bissonnette and Bergeron, 2006). These results upstretched the prospect of concomitant administration of diagnostics and multiple forms of therapy.

Photoablation therapy is used for cancer treatment and is divided into two types, photothermal therapy (PTT) and photodynamic therapy (PDT) (Zheng et al., 2008). Among these, PTT is an excellent contender for cancer treatment and focuses on the use of photo-induced heat to kill cancer cells (Her et al., 2017). While in PDT treatment, a poorly soluble drug and visible light irradiations are used at certain wavelengths for generating reactive oxygen species such as singlet oxygen to kill cancer cells (McNamara and Tofail, 2017). PTT is an attractive method owing to advantages such as the safety of nontarget regions, its minimally invasive nature, fast recovery, and so on. Magnetic nanoparticles generate heat when placed in a varying magnetic field due to magnetic hysteresis loss (Neelrelaxation and Brown-relaxation). This led scientists to apply these magnetic in hyperthermia treatment which is considered as a supplementary treatment to radiation, chemotherapy and surgery in cancer therapy (Marangon et al., 2017). Magnetic induction hyperthermia is based on the fact that when alternating magnetic field is applied to magnetic nanoparticles, induced currents are generated and consequently heat is produced in magnetic nanoparticles. Based on this principal, when magnetic fluids are exposed to alternating magnetic field, the fluids turn into powerful heat sources, destroying tumor cells, since these cells are more sensitive to temperatures more than $41^{\circ} \mathrm{C}$ than their normal counterparts (Gomer et al., 2016). PTT has certain disadvantages as well, like the need for high-power lasers and the thermal destruction of cancer selective cell lines. Recently, PDT has attracted considerable attention in cancer treatment, as it is a non-invasive method, low energy light, site-specific tumor targeting and negligible side effects. Due to the poor solubility of drugs in water, these tend to accumulate in physiological media, hence indicating the need to work on developing improved drug delivery systems.

Photoacoustic imaging is a new method which is a combination of optical and acoustic imaging of burns, studying blood vessels, melanoma sites etc. This technique gives indepth analysis of various tissues, e.g., breast cancer cells, brain cancer cells and tumor monitoring (Sakellari et al., 2016). In photoacoustic tomography, the laser system used for photoacoustic imaging $(532 \mathrm{~nm})$ has great promise for non-invasive early diagnosis and the imaging of tumor cells and tissues. Gold nanoparticles have proven to be excellent non-invasive contrasting agents for early diagnosis of tumor by photoacoustic imaging. Computed tomography is one of the most common hospital's diagnostic tools; it is another excellent imaging method for grabbing anatomical information. It is a choice made for clinical applications because of cost, efficiency, availability, deep tissue penetration and high spatial resolution. In this method, gold nanoparticles can be used as contrasting agents because of the high X-ray absorption, lower toxicity and slow clearance in the body. it was also suggested that gold nanoparticles may replace conventional iodine based contrasting agents as these reagents display renal toxicity and fast excretion. Gold nanoparticles displayed excellent biocompatibility, enhanced stability and increased accumulation in computed tomography tumor imaging (Kobayashi et al., 2016). Ultrasound imaging is a clinical diagnostic tool extensively used due to interesting features such as being non-invasive, cost-effective and portable. Like all the other diagnostic imaging methods, contrasting agents can be adopted to enhance imaging precision in ultrasound imaging. In this method, microscale fluorocarbon bubbles are typically used as contrasting agents: in literature, ultrasound imaging contrasting agents should feature four characteristics, easy fabrication, easy administration, high biosafety and excellent echogenicity.

\section{ATHEROSCLEROSIS}

Atherosclerosis, a complex disease and one of the leading causes of death in the developed world (Chen et al., 2016). It is a chronic inflammation and remodeling processes which leads to the stenosis of the aorta; generally, it's a gradual process spanning 
over decades, but under certain conditions, it grows rapidly leading to an ischaemia.

In recent years, an extraordinary number of research projects have been funded to make advances in the diagnosis, prognosis and treatment of this fatal disease (Yildirim et al., 2016). Pathological detection of atherosclerosis has improved significantly with the use of magnetic resonance imaging due to contrasting agents and their excellent spatial resolution and average sensitivity; modern-day research in this area is probing new contrasting agents for improved imaging (Fernández-Ruiz, 2016). Other techniques used to detect early-stage atherosclerosis include computed tomography, photoacoustic tomography, positron emission tomography, single-photon emission computed tomography and fluorescence molecular tomography and every technique has pluses as well as minuses. For example, some methods give outstanding sensitivity but low resolution while others have excellent resolution but lower sensitivity. Magnetic nanomaterials have shown the promise to implement magnetic nanomaterials binding to specific surfaces to reduce the detection time (Brown et al., 2016).

As discussed earlier, iron oxide magnetic nanoparticles' magnetic moments rotate rapidly when exposed to external magnetic field and the magnetic flux gets enhanced; and upon the removal of the magnetic field, Brownian motion causes randomization of the magnetic field; this condition is superparamagentism which is observable only at nanoscale. Commonly used as good contrasting agents are gadoliniumbased substances; with adverse characteristics including cytotoxicity and the persistent accumulation of gadolinium. Iron oxide magnetic nanoparticles have better results as magnetic resonance imaging contrasting agents when compared with gadolinium and manganese oxide nanoparticles (Li et al., 2016). Gadolinium-based formulations are still dominating contrasting agents; however, after a careful survey of literature and recent clinical trials evidences, the future of iron oxide magnetic nanoparticles is highly promissory for diagnostic imaging guided therapy with the suitable incorporation of specific ligands to well-defined pathologies. So far, we have learnt that atherosclerosis may occur anywhere in the vascular system and the lack of sensitivity in the use of commercially available contrasting agents is a major challenge for the early diagnosis of the plaque which usually possesses a thickness and length. Positron emission tomography has low resolution for the detection of atherosclerotic plaque while the magnetic resonance imaging technique has excellent resolution but lacks sensitivity for pertinent screening. Superparamagnetic iron oxide nanoparticles synthesized by polyol method were successfully applied to mice as an MRI contrasting agent with promising results $5 \mathrm{~h}$ after post-injection treatment (Wang et al., 2016). More recently, the in vivo application of magnetic nanoparticles in the range of $90 \mathrm{~nm}$ allowed for excellent visuals of atherosclerotic plaque in mice; similarly, the NIRfluorescence based method approach have also been applied with interesting results (Cuadrado et al., 2016; Yoo et al., 2016; Schneider and Lassalle, 2017). In all three techniques, it was observed that the magnetic nanoparticles got accumulated in the atherosclerotic area.

\section{CONCLUDING REMARKS}

Magnetic nanoparticles possess a great promise in drugdelivery systems due to their unique properties to overcome some of the problems to efficiently target diverse cell types. The future is encouraging as well as challenging and novel research ideas are needed to be worked out to prevent its limitations for the therapy of more diseases. Iron oxide magnetic nanoparticles possess a strong candidature for aqueous/nonaqueous phase solubility with great potential in medical applications. To achieve this, several factors play a key-role including suitable precursors, $\mathrm{pH}$ of the medium, coating agents and solvents for the synthesis of magnetic nanoparticles. Aqueous phase solubility can be significantly improved by using water-soluble surface functionalization agents via thermal decomposition, co-precipitation, microwave and high-temperature methods.

MRI is a non-invasive imaging technique used to study anatomical site and biologically compatible nanomaterials aid in detailed images for more accurate diagnosis. Magnetic nanoparticles act as contrasting agents which are advantageous to improve the contrast in these images. Magnetic iron oxide nanoparticles have been the key focus in this review article; which are stabilized by increasing the hydrophilicity through coatings onto the metal surface followed by the attachment of additional ligands like antibodies etc. Next is the specific linking to signal-secreting cells which permits specific agglomeration of nanoparticles to the inflamed/tumor bearing site. Contrast is still a challenge in MRI and new improvements are being sought through labeled magnetic nanoparticles with a fluorescent protein, such as green fluorescent protein or red fluorescent protein; giving rise to a distinct color of the target area under investigation. This research requires more intense in vivo studies which will lead to improve the biological compatibilities and any possible negative side effects associated with the injection of magnetic nanoparticles. Magnetic iron oxide nanoparticles comparatively proved to be a highly reliable and better theranostic option as gadolinium complexes gives excellent contrast, but these are nephrotoxic.

Finally, the scientific information collected here while compiling this review opens novel insights into the role of magnetic nanoparticles to develop nanocarriers enabled to increase the efficiency of the modern-day theranostics.

\section{AUTHOR CONTRIBUTIONS}

SG compiled this review article with collective scholarly contribution of all the co-authors. 


\section{REFERENCES}

Ahmed, N., Fessi, H., and Elaissari, A. (2012). Theranostic applications of nanoparticles in cancer. Drug Discovery Today 17, 928-934. doi: 10.1016/j.drudis.2012.03.010

Ali, A., Hira Zafar, M. Z., ul Haq, I., Phull, A. R., Ali, J. S., and Hussain, A. (2016). Synthesis, characterization, applications, and challenges of iron oxide nanoparticles. Nanotechnol. Sci. Appl. 9:49. doi: 10.2147/NSA.S99986

Anselmo, A. C., and Mitragotri, S. (2017). Impact of particle elasticity on particle-based drug delivery systems. Adv. Drug Delivery Rev. 108, 51-67. doi: 10.1016/j.addr.2016.01.007

Awwad, A. M., Salem, N. M., and Abdeen, A. O. (2013). Green synthesis of silver nanoparticles using carob leaf extract and its antibacterial activity. Int. J. Ind. Chem. 4:29. doi: 10.1186/2228-5547-4-29

Bai, H. J., Zhang, Z. M., Guo, Y., and Yang, G. E. (2009). Biosynthesis of cadmium sulfide nanoparticles by photosynthetic bacteria Rhodopseudomonas palustris. Colloids Surfaces B Biointerfaces 70, 142-146. doi: 10.1016/j.colsurfb.2008.12.025

Bansal, R., Nagórniewicz, B., Storm, G., and Prakash, J. (2017). Relaxincoated superparamagnetic iron-oxide nanoparticles as a novel theranostic approach for the diagnosis and treatment of liver fibrosis. J. Hepatol. 66:S43. doi: 10.1016/S0168-8278(17)30348-3

Baranwal, A., Mahato, K., Srivastava, A., Maurya, P. K., and Chandra, P. (2016). Phytofabricated metallic nanoparticles and their clinical applications. RSC Adv. 6, 105996-106010. doi: 10.1039/c6ra23411a

Barrow, M., Taylor, A., Murray, P., Rosseinsky, M. J., and Adams, D. J. (2015). Design considerations for the synthesis of polymer coated iron oxide nanoparticles for stem cell labelling and tracking using MRI. Chem. Soc. Rev. 44, 6733-6748. doi: 10.1039/c5cs00331h

Baxter-Plant, V. S., Mikheenko, I. P., and Macaskie, L. E. (2003). Sulphate-reducing bacteria, palladium and the reductive dehalogenation of chlorinated aromatic compounds. Biodegradation 14, 83-90. doi: 10.1023/A:1024084611555

Bissonnette, L., and Bergeron, M. G. (2006). Next revolution in the molecular theranostics of infectious diseases: microfabricated systems for personalized medicine. Expert Rev. Mol. Diagnost. 6, 433-450. doi: 10.1586/14737159. 6.3 .433

Boyer, C., Whittaker, M. R., Bulmus, V., Liu, J., and Davis, T. P. (2010). The design and utility of polymer-stabilized iron-oxide nanoparticles for nanomedicine applications. NPG Asia Mater. 2:23. doi: 10.1038/asiamat.2010.6

Brown, A. J., Teng, Z., Evans, P. C., Gillard, J. H., Samady, H., and Bennett, M. R. (2016). Role of biomechanical forces in the natural history of coronary atherosclerosis. Nat. Rev. Cardiol. 13:210. doi: 10.1038/nrcardio.2015.203

Bucak, S., Yavuztürk, B., and Sezer, A. D. (2012). "Magnetic nanoparticles: synthesis, surface modifications and application in drug delivery," in Recent Advances in Novel Drug Carrier Systems (IntechOpen). Available online at: https://www.cd-bioparticles.com/t/Drug-Delivery_51.html (accessed October 22, 2017).

Bünzli, J. C. G. (2016). Lanthanide light for biology and medical diagnosis. J. Luminescence 170, 866-878. doi: 10.1016/j.jlumin.2015.07.033

Buzug, T. M. (2010). "Magnetic nanoparticles: particle science, imaging technology, and clinical applications," in Proceedings of the First International Workshop on Magnetic Particle Imaging. Singapore: World Scientific.

Cai, H., An, X., Cui, J., Li, J., Wen, S., Li, K., et al. (2013). Facile hydrothermal synthesis and surface functionalization of polyethyleneimine-coated iron oxide nanoparticles for biomedical applications. ACS Appl. Mater. Interfaces 5, 1722-1731. doi: 10.1021/am302883m

Chen, Y., Ma, M., Chen, H., and Shi, J. (2016). "Multifunctional hollow mesoporous silica nanoparticles for MR/US imaging-guided tumor therapy," in Advances in Nanotheranostics II, ed Z. Dai (Singapore: Springer), 189-222. doi: 10.1007/978-981-10-0063-8_6

Cuadrado, I., Saura, M., Castejón, B., Martin, A. M., Herruzo, I., Balatsos, N., et al. (2016). Preclinical models of atherosclerosis. The future of Hybrid PET/MR technology for the early detection of vulnerable plaque. Expert Rev. Mol. Med. 18:e6. doi: 10.1017/erm.2016.5

de Toledo, L. D. A. S., Rosseto, H. C., and Bruschi, M. L. (2018). Iron oxide magnetic nanoparticles as antimicrobials for therapeutics. Pharmaceut. Dev. Technol. 23, 316-323. doi: 10.1080/10837450.2017.1337793
Deshmukh, R., and Niederberger, M. (2017). Mechanistic aspects in the formation, growth and surface functionalization of metal oxide nanoparticles in organic solvents. Chem. Eur. J. 23, 8542-8570. doi: 10.1002/chem.201605957

Dhal, S., Mohanty, A., Yadav, I., Uvanesh, K., Kulanthaivel, S., Banerjee, I., et al. (2017). Magnetic nanoparticle incorporated oleogel as iontophoretic drug delivery system. Colloids Surfaces B Biointerfaces 157, 118-129. doi: 10.1016/j.colsurfb.2017.05.061

Dong, H., Chen, Y. C., and Feldmann, C. (2015). Polyol synthesis of nanoparticles: status and options regarding metals, oxides, chalcogenides, and non-metal elements. Green Chem. 17, 4107-4132. doi: 10.1039/C5GC00943J

Drozdov, A. S., Ivanovski, V., Avnir, D., and Vinogradov, V. V. (2016). A universal magnetic ferrofluid: nanomagnetite stable hydrosol with no added dispersants and at neutral pH. J. Colloid Interface Sci. 468, 307-312. doi: 10.1016/j.jcis.2016.01.061

Effenberger, F. B., Couto, R. A., Kiyohara, P. K., Machado, G., Masunaga, S. H., Jardim, R. F., et al. (2017). Economically attractive route for the preparation of high quality magnetic nanoparticles by the thermal decomposition of iron (III) acetylacetonate. Nanotechnology 28:115603. doi: 10.1088/1361-6528/aa5ab0

Elrouby, M., Abdel-Mawgoud, A. M., and El-Rahman, R. A. (2017). Synthesis of iron oxides nanoparticles with very high saturation magnetization form TEA$\mathrm{Fe}$ (III) complex via electrochemical deposition for supercapacitor applications. J. Mol. Struct. 1147, 84-95. doi: 10.1016/j.molstruc.2017.06.092

Estelrich, J., Sánchez-Martín, M. J., and Busquets, M. A. (2015). Nanoparticles in magnetic resonance imaging: from simple to dual contrast agents. Int. J. Nanomed. 10:1727. doi: 10.2147/ijn.s76501

Fernández-Ruiz, I. (2016). Immune system and cardiovascular disease. Nat. Rev. Cardiol. 13:503. doi: 10.1038/nrcardio.2016.127

Fish, M. B., Fromen, C. A., Lopez-Cazares, G., Golinski, A. W., Scott, T. F., Adili, R., et al. (2017). Exploring deformable particles in vascular-targeted drug delivery: softer is only sometimes better. Biomaterials 124, 169-179. doi: 10.1016/j.biomaterials.2017.02.002

Freitas, J. C. D., Branco, R. M., Lisboa, I. G. O., Costa, T. P. D., Campos, M. G. N., Jafelicci Júnior, M., et al. (2015). Magnetic nanoparticles obtained by homogeneous coprecipitation sonochemically assisted. Mater. Res. 18, 220-224. doi: 10.1590/1516-1439.366114

Funke, C., and Szeri, A. J. (eds.). (2017). "Osmolarity as a contributing factor in topical drug delivery," in APS Division of Fluid Dynamics Meeting Abstracts (Vancouver, BC).

Gomer, C. J., Luna, M., Ferrario, A., Rucker, N., and Wong, S. (2016). “The tumor microenvironment modulates responsiveness to photodynamic therapy," in Photodynamic Medicine: From Bench to Clinic, eds H. Kostron and T. Hasan (The Royal Society of Chemistry), 87-99. doi: 10.1039/9781782626824-00087

Guo, Y., Wang, Z., Shao, H., and Jiang, X. (2013). Hydrothermal synthesis of highly fluorescent carbon nanoparticles from sodium citrate and their use for the detection of mercury ions. Carbon 52, 583-589. doi: 10.1016/j.carbon.2012.10.028

Gutiérrez, L., Costo, R., Grüttner, C., Westphal, F., Gehrke, N., Heinke, D., et al. (2015). Synthesis methods to prepare single-and multi-core iron oxide nanoparticles for biomedical applications. Dalton Transac. 44, 2943-2952. doi: 10.1039/C.4D.T.03013C

Habibi, N., Pastorino, L., Babolmorad, G., Ruggiero, C., Guda, T., and Ong, J. L. (2017). Polyelectrolyte multilayers and capsules: S-layer functionalization for improving stability and biocompatibility. J. Drug Delivery Sci. Technol. 38, 1-8. doi: 10.1039/C5CS00331H

Hachani, R., Lowdell, M., Birchall, M., Hervault, A., Mertz, D., Begin-Colin, S., et al. (2016). Polyol synthesis, functionalisation, and biocompatibility studies of superparamagnetic iron oxide nanoparticles as potential MRI contrast agents. Nanoscale 8, 3278-3287. doi: 10.1039/C5NR 03867G

Hasany, S., Abdurahman, N., Sunarti, A., and Jose, R. (2013). Magnetic iron oxide nanoparticles: chemical synthesis and applications review. Curr. Nanosci. 9, 561-575. doi: 10.2174/15734137113099990085

Hemery, G., Keyes A. C. Jr., Garaio, E., Rodrigo, I., Garcia, J. A., Plazaola, F., et al. (2017). Tuning sizes, morphologies, and magnetic properties of monocore versus multicore iron oxide nanoparticles through the controlled addition of water in the polyol synthesis. Inorg. Chem. 56, 8232-8243. doi: 10.1021/acs.inorgchem.7b00956 
Her, S., Jaffray, D. A., and Allen, C. (2017). Gold nanoparticles for applications in cancer radiotherapy: mechanisms and recent advancements. Adv. Drug Delivery Rev. 109, 84-101. doi: 10.1016/j.addr.2015.12.012

Ho, D., Sun, X., and Sun, S. (2011). Monodisperse magnetic nanoparticles for theranostic applications. Accounts Chem. Res. 44, 875-882. doi: $10.1021 /$ ar200090c

Hola, K., Markova, Z., Zoppellaro, G., Tucek, J., and Zboril, R. (2015). Tailored functionalization of iron oxide nanoparticles for MRI, drug delivery, magnetic separation and immobilization of biosubstances. Biotechnol. Adv. 33, 1162-1176. doi: 10.1016/j.biotechadv.2015.02.003

Huber, D. L. (2005). Synthesis, properties, and applications of iron nanoparticles. Small 1, 482-501. doi: 10.1002/smll.200500006

Hufschmid, R., Arami, H., Ferguson, R. M., Gonzales, M., Teeman, E., Brush, L. N., et al. (2015). Synthesis of phase-pure and monodisperse iron oxide nanoparticles by thermal decomposition. Nanoscale 7, 11142-11154. doi: 10.1039/C5NR01651G

Hyeon, T., Piao, Y., and Park, Y. I. (2016). U.S. Patent No. 9,352,058. Washington, DC: U.S. Patent and Trademark Office.

Iravani, S. (2011). Green synthesis of metal nanoparticles using plants. Green Chem. 13, 2638-2650. doi: 10.1039/clgc15386b

Jiles, D. (2015). Introduction to Magnetism and Magnetic Materials. Boca Raton, FL: CRC Press.

Kandasamy, R. (2017). A novel single step synthesis and surface functionalization of iron oxide magnetic nanoparticles and thereof for the copper removal from pigment industry effluent. Separation Purification Technol. 188, 458-467. doi: 10.1016/j.seppur.2017.07.059

Khandhar, A. P., Keselman, P., Kemp, S. J., Ferguson, R. M., Goodwill, P. W., Conolly, S. M., et al. (2017). Evaluation of PEG-coated iron oxide nanoparticles as blood pool tracers for preclinical magnetic particle imaging. Nanoscale 9, 1299-1306. doi: 10.1039/C6NR08468K

Kharisov, B. I., Dias, H. R., Kharissova, O. V., Vázquez, A., Pena, Y., and Gomez, I. (2014). Solubilization, dispersion and stabilization of magnetic nanoparticles in water and non-aqueous solvents: recent trends. RSC Adv. 4, 45354-45381. doi: $10.1039 / \mathrm{c} 4 \mathrm{ra} a 6902 \mathrm{a}$

Kharissova, O. V., Dias, H. R., Kharisov, B. I., Pérez, B. O., and Pérez, V. M. J. (2013). The greener synthesis of nanoparticles. Trends Biotechnol. 31, 240-248. doi: 10.1016/j.tibtech.2013.01.003

Kobayashi, T., Ito, A., and Honda, H. (2016). "Magnetic nanoparticlemediated hyperthermia and induction of anti-tumor immune responses," in Hyperthermic Oncology from Bench to Bedside, eds S. Kokura, T. Yoshikawa, and T. Ohnishi (Singapore: Springer), 137-150. doi: 10.1007/978-981-10-0719-4_13

Kovár, D., Malá, A., Mlčochová, J., Kalina, M., Fohlerová, Z., Hlaváček, A., et al. (2017). Preparation and characterisation of highly stable iron oxide nanoparticles for magnetic resonance imaging. J. Nanomater. 2017:7859289. doi: $10.1155 / 2017 / 7859289$

Kumar, A., Saxena, A., De, A., Shankar, R., and Mozumdar, S. (2013). Facile synthesis of size-tunable copper and copper oxide nanoparticles using reverse microemulsions. Rsc Adv. 3, 5015-5021. doi: 10.1039/c3ra23455j

Langer, R. (1990). New methods of drug delivery. Science 249, 1527-1533. doi: $10.1126 /$ science. 2218494

Laurent, S., Forge, D., Port, M., Roch, A., Robic, C., Vander Elst, L., et al. (2008). Magnetic iron oxide nanoparticles: synthesis, stabilization, vectorization, physicochemical characterizations, and biological applications. Chem. Rev. 108, 2064-2110. doi: 10.1021/cr068445e

Li, J., Wang, S., Shi, X., and Shen, M. (2017). Aqueous-phase synthesis of iron oxide nanoparticles and composites for cancer diagnosis and therapy. Adv. Colloid Interface Sci. 249, 374-385. doi: 10.1016/j.cis.2017.02.009

Li, L., Jiang, W., Luo, K., Song, H., Lan, F., Wu, Y., et al. (2013). Superparamagnetic iron oxide nanoparticles as MRI contrast agents for non-invasive stem cell labeling and tracking. Theranostics 3:595. doi: 10.7150/thno.5366

Li, X., Wang, C., Tan, H., Cheng, L., Liu, G., Yang, Y., et al. (2016). Gold nanoparticles-based SPECT/CT imaging probe targeting for vulnerable atherosclerosis plaques. Biomaterials 108, 71-80. doi: $10.1016 /$ j.biomaterials.2016.08.048

Lin, L., Starostin, S. A., Hessel, V., and Wang, Q. (2017). Synthesis of iron oxide nanoparticles in microplasma under atmospheric pressure. Chem. Eng. Sci. 168, 360-371. doi: 10.1016/j.ces.2017.05.008
Liu, Y., Yang, J., Xie, M., Xu, J., Li, Y., Shen, H., et al. (2017). Synthesis of polyethyleneimine-modified magnetic iron oxide nanoparticles without adding base and other additives. Mater. Lett. 193, 122-125. doi: 10.1016/j.matlet.2017.01.056

Lodhia, J., Mandarano, G., Ferris, N. J., Eu, P., and Cowell, S. F. (2010). Development and use of iron oxide nanoparticles (Part 1): synthesis of iron oxide nanoparticles for MRI. Biomed. Imag. Intervent. J. 6:e12. doi: 10.2349/biij.6.2.e12

Lu, A. H., Salabas, E. L., and Schüth, F. (2007). Magnetic nanoparticles: synthesis, protection, functionalization, and application. Angew. Chem. Int. Ed. 46, 1222-1244. doi: 10.1002/anie.200602866

Madadlou, A., Jaberipour, S., and Eskandari, M. H. (2014). Nanoparticulation of enzymatically cross-linked whey proteins to encapsulate caffeine via microemulsification/heat gelation procedure. LWT-Food Sci. Technol. 57, 725-730. doi: 10.1016/j.lwt.2014.02.041

Mahmed, N., Heczko, O., Söderberg, O., and Hannula, S. P. (2011). "Room temperature synthesis of magnetite $\left(\mathrm{Fe}_{3} \mathrm{O}_{4}\right)$ nanoparticles by a simple reverse co-precipitation method," in IOP Conference Series: Materials Science and Engineering (Bristol: IOP Publishing). doi: 10.1088/1757-899X/18/3/032020

Makarov, V. V., Makarova, S. S., Love, A. J., Sinitsyna, O. V., Dudnik, A. O., Yaminsky, I. V., et al. (2014). Biosynthesis of stable iron oxide nanoparticles in aqueous extracts of Hordeum vulgare and Rumex acetosa plants. Langmuir 30, 5982-5988. doi: 10.1021/la5011924

Malo de Molina, P., Zhang, M., Bayles, A. V., and Helgeson, M. E. (2016). Oil-inwater-in-oil multinanoemulsions for templating complex nanoparticles. Nano Lett. 16, 7325-7332. doi: 10.1021/acs.nanolett.6b02073

Marangon, I., Silva, A. A., Guilbert, T., Kolosnjaj-Tabi, J., Marchiol, C., and Natkhunarajah, S. (2017). Tumor stiffening, a key determinant of tumor progression, is reversed by nanomaterial-induced photothermal therapy. Theranostics 7:329. doi: 10.7150/thno.17574

Martínez-Cabanas, M., López-García, M., Barriada, J. L., Herrero, R., and de Vicente, M. E. S. (2016). Green synthesis of iron oxide nanoparticles. Development of magnetic hybrid materials for efficient $\mathrm{As}(\mathrm{V})$ removal. Chem. Eng. J. 301, 83-91. doi: 10.1016/j.cej.2016.04.149

Maryanti, E., Damayanti, D., and Gustian, I. (2014). Synthesis of $\mathrm{ZnO}$ nanoparticles by hydrothermal method in aqueous rinds extracts of Sapindus rarak DC. Mater. Lett. 118, 96-98. doi: 10.1016/j.matlet.2013.12.044

Mascolo, M., Pei, Y., and Ring, T. (2013). Room temperature co-precipitation synthesis of magnetite nanoparticles in a large $\mathrm{pH}$ window with different bases. Materials 6, 5549-5567. doi: 10.3390/ma6125549

McMahon, M. T., and Bulte, J. W. (2018). Two decades of dendrimers as versatile MRI agents: a tale with and without metals. Wiley Interdisciplinary Rev. Nanomed. Nanobiotechnol. 10:e1496. doi: 10.1002/wnan.1496

McNamara, K., and Tofail, S. A. (2017). Nanoparticles in biomedical applications. Adv. Phys. 2, 54-88. doi: 10.1080/23746149.2016.1254570

Mody, V. V., Cox, A., Shah, S., Singh, A., Bevins, W., and Parihar, H. (2014). Magnetic nanoparticle drug delivery systems for targeting tumor. Appl. Nanosci. 4, 385-392. doi: 10.1007/s13204-013-0216-y

Mohammed, L., Gomaa, H. G., Ragab, D., and Zhu, J. (2017). Magnetic nanoparticles for environmental and biomedical applications: a review. Particuology 30, 1-14. doi: 10.1016/j.partic.2016.06.001

Monsalve, A., Vicente, J., Grippin, A., and Dobson, J. (2017). Poly (lactic acid) magnetic microparticle synthesis and surface functionalization. IEEE Magn. Lett. 8, 1-5. doi: 10.1109/LMAG.2017.2726505

Naghibi, S., Sani, M. A. F., and Hosseini, H. R. M. (2014). Application of the statistical Taguchi method to optimize $\mathrm{TiO}_{2}$ nanoparticles synthesis by the hydrothermal assisted sol-gel technique. Ceramics Int. 40, 4193-4201. doi: 10.1016/j.ceramint.2013.08.077

Nassar, M. Y., Ahmed, I. S., Mohamed, T. Y., and Khatab, M. (2016). A controlled, template-free, and hydrothermal synthesis route to sphere-like $\alpha$ Fe 2 O 3 nanostructures for textile dye removal. RSC Adv. 6, 20001-20013. doi: 10.1039/C5RA26112K

Njagi, E. C., Huang, H., Stafford, L., Genuino, H., Galindo, H. M., Collins, J. B., et al. (2010). Biosynthesis of iron and silver nanoparticles at room temperature using aqueous sorghum bran extracts. Langmuir 27, 264-271. doi: 10.1021/la103190n

Pang, Y. L., Lim, S., Ong, H. C., and Chong, W. T. (2016). Research progress on iron oxide-based magnetic materials: synthesis techniques and photocatalytic applications. Ceramics Int. 42, 9-34. doi: 10.1016/j.ceramint.2015.08.144 
Patsula, V., Kosinová, L., Lovri,c, M., Ferhatovic Hamzic, L., Rabyk, M., Konefal, R., et al. (2016). Superparamagnetic $\mathrm{Fe}_{3} \mathrm{O}_{4}$ nanoparticles: synthesis by thermal decomposition of iron (III) glucuronate and application in magnetic resonance imaging. ACS Appl. Mater. Interfaces 8, 7238-7247. doi: $10.1021 /$ acsami.5b12720

Rai, M., Maliszewska, I., Ingle, A., Gupta, I., and Yadav, A. (2015). "Diversity of microbes in synthesis of metal nanoparticles: progress and limitations," in BioNanoparticles: Biosynthesis and Sustainable Biotechnological Implications, ed O. V. Singh (Chichester: Wiley), 1-30. doi: 10.1002/9781118677629.ch1

Rajiv, P., Bavadharani, B., Kumar, M. N., and Vanathi, P. (2017). Synthesis and characterization of biogenic iron oxide nanoparticles using green chemistry approach and evaluating their biological activities. Biocatalysis Agricult. Biotechnol. 12, 45-49. doi: 10.1016/j.bcab.2017.08.015

Riaz, S., Naseem, S., and Han, X. (2015). "Citric acid coated iron oxide nanoparticles-Structural and magnetic properties," in 2015 IEEE International Magnetics Conference (INTERMAG) (IEEE). doi: 10.1109/INTMAG.2015.7157349

Sakellari, D., Brintakis, K., Kostopoulou, A., Myrovali, E., Simeonidis, K., Lappas, A., et al. (2016). Ferrimagnetic nanocrystal assemblies as versatile magnetic particle hyperthermia mediators. Mater. Sci. Eng. C 58, 187-193. doi: 10.1016/j.msec.2015.08.023

Sathya, K., Saravanathamizhan, R., and Baskar, G. (2017). Ultrasound assisted phytosynthesis of iron oxide nanoparticle. Ultrasonics Sonochem. 39, 446-451. doi: 10.1016/j.ultsonch.2017.05.017

Schneider, M. G. M., and Lassalle, V. L. (2017). Magnetic iron oxide nanoparticles as novel and efficient tools for atherosclerosis diagnosis. Biomed. Pharmacother. 93, 1098-1115. doi: 10.1016/j.biopha.2017.07.012

Seeli, D. S., and Prabaharan, M. (2017). Guar gum oleate-graft-poly (methacrylic acid) hydrogel as a colon-specific controlled drug delivery carrier. Carbohydrate Polymers 158, 51-57. doi: 10.1016/j.carbpol.2016.11.092

Shah, M., Fawcett, D., Sharma, S., Tripathy, S., and Poinern, G. (2015). Green synthesis of metallic nanoparticles via biological entities. Materials 8, 7278-7308. doi: 10.3390/ma8115377

Smith, T. W., and Wychick, D. (1980). Colloidal iron dispersions prepared via the polymer-catalyzed decomposition of iron pentacarbonyl. J. Phys. Chem. 84, 1621-1629. doi: 10.1021/j100449a037

Sood, A., Arora, V., Shah, J., Kotnala, R. K., and Jain, T. K. (2017). Multifunctional gold coated iron oxide core-shell nanoparticles stabilized using thiolated sodium alginate for biomedical applications. Mater. Sci. Eng. C 80, 274-281. doi: 10.1016/j.msec.2017.05.079

Sun, Z., Worden, M., Thliveris, J. A., Hombach-Klonisch, S., Klonisch, T., van Lierop, J., et al. (2016). Biodistribution of negatively charged iron oxide nanoparticles (IONPs) in mice and enhanced brain delivery using lysophosphatidic acid (LPA). Nanomed. Nanotechnol. Biol. Med. 12, 1775-1784. doi: 10.1016/j.nano.2016.04.008

Surowiec, Z., Budzynski, M., Durak, K., and Czernel, G. (2017). Synthesis and characterization of iron oxide magnetic nanoparticles. Nukleonika 62, 73-77. doi: 10.1515/nuka-2017-0009

Taboada, E., Rodríguez, E., Roig, A., Oró, J., Roch, A., and Muller, R. N. (2007). Relaxometric and magnetic characterization of ultrasmall iron oxide nanoparticles with high magnetization. Evaluation as potential T 1 magnetic resonance imaging contrast agents for molecular imaging. Langmuir 23, 45834588. doi: 10.1021/la063415s

Tadic, M., Panjan, M., Damnjanovic, V., and Milosevic, I. (2014). Magnetic properties of hematite $\left(\alpha-\mathrm{Fe}_{2} \mathrm{O}_{3}\right)$ nanoparticles prepared by hydrothermal synthesis method. Appl. Surface Sci. 320, 183-187. doi: 10.1016/j.apsusc.2014.08.193

Tombácz, E., Turcu, R., Socoliuc, V., and Vékás, L. (2015). Magnetic iron oxide nanoparticles: recent trends in design and synthesis of magnetoresponsive nanosystems. Biochem. Biophys. Res. Commun. 468, 442-453. doi: 10.1016/j.bbrc.2015.08.030

Veiseh, O., Gunn, J. W., and Zhang, M. (2010). Design and fabrication of magnetic nanoparticles for targeted drug delivery and imaging. Adv. Drug Delivery Rev. 62, 284-304. doi: 10.1016/j.addr.2009.11.002

Wang, Y., Chen, J., Yang, B., Qiao, H., Gao, L., Su, T., et al. (2016). In vivo MR and fluorescence dual-modality imaging of atherosclerosis characteristics in mice using profilin-1 targeted magnetic nanoparticles. Theranostics 6, 272. doi: $10.7150 /$ thno. 13350

Watt, J., Bleier, G. C., Austin, M. J., Ivanov, S. A., and Huber, D. L. (2017) Non-volatile iron carbonyls as versatile precursors for the synthesis of ironcontaining nanoparticles. Nanoscale 9, 6632-6637. doi: 10.1039/C7NR01028A

Wee, S.-B., Oh, H.-C., Kim, T.-G., An, G.-S., and Choi, S.-C. (2017). Role of $\mathrm{N}$-methyl-2-pyrrolidone for preparation of $\mathrm{Fe}_{3} \mathrm{O}_{4} @ \mathrm{SiO}_{2}$ controlled the shell thickness. J. Nanoparticle Res. 19:143. doi: 10.1007/s11051-017-3813-y

Williams, M. J., Sánchez, E., Aluri, E. R., Douglas, F. J., MacLaren, D. A., Collins, O. M., et al. (2016). Microwave-assisted synthesis of highly crystalline, multifunctional iron oxide nanocomposites for imaging applications. RSC Adv. 6, 83520-83528. doi: 10.1039/C6RA11819D

Xiao, Y.-D., Paudel, R., Liu, J., Ma, C., Zhang, Z.-S., and Zhou, S.-K. (2016). MRI contrast agents: classification and application. Int. J. Mol. Med. 38, 1319-1326. doi: 10.3892/ijmm.2016.2744

Xu, X., Yadav, N. N., Song, X., McMahon, M. T., Jerschow, A., Van Zijl, P. C., et al. (2016). Screening CEST contrast agents using ultrafast CEST imaging. J. Magn. Resonance 265, 224-229. doi: 10.1016/j.jmr.2016.02.015

Yang, K. M., Cho, H. I., Choi, H. J., and Piao, Y. (2014). Synthesis of water well-dispersed PEGylated iron oxide nanoparticles for MR/optical lymph node imaging. J. Mater. Chem. B 2, 3355-3364. doi: 10.1039/C4TB0 $0084 \mathrm{~F}$

Yang, X. C., Shang, Y. L., Li, Y. H., Zhai, J., Foster, N. R., Li, Y. X., et al. (2014). Synthesis of monodisperse Iron oxide nanoparticles without surfactants. J. Nanomater. 2014:231. doi: 10.1155/2014/740856

Yelenich, O. V., Solopan, S. O., Kolodiazhnyi, T. V., Greneche, J. M., and Belous, A. G. (2015). "Synthesis of iron oxide nanoparticles by different methods and study of their properties," in Solid State Phenomena, Vol. 230 (Zurich: Trans Tech Publications), 108-113. doi: 10.4028/www.scientific.net/SSP.230.108

Yildirim, A., Chattaraj, R., Blum, N. T., and Goodwin, A. P. (2016). Understanding acoustic cavitation initiation by porous nanoparticles: toward nanoscale agents for ultrasound imaging and therapy. Chem. Mater. 28, 5962-5972. doi: 10.1021/acs.chemmater.6b02634

Yoo, S. P., Pineda, F., Barrett, J. C., Poon, C., Tirrell, M., and Chung, E. J. (2016). Gadolinium-functionalized peptide amphiphile micelles for multimodal imaging of atherosclerotic lesions. ACS Omega 1, 996-1003. doi: 10.1021/acsomega.6b00210

Yu, S. M., Laromaine, A., and Roig, A. (2014). Enhanced stability of superparamagnetic iron oxide nanoparticles in biological media using a pH adjusted-BSA adsorption protocol. J. Nanopart. Res. 16:2484. doi: 10.1007/s11051-014-2484-1

Yu, W., Sun, T. W., Ding, Z., Qi, C., Zhao, H., Chen, F., et al. (2017). Copperdoped mesoporous hydroxyapatite microspheres synthesized by a microwavehydrothermal method using creatine phosphate as an organic phosphorus source: application in drug delivery and enhanced bone regeneration. J. Mater. Chem. B 5, 1039-1052. doi: 10.1039/C6TB02747D

Zhao, H., Liu, R., Zhang, Q., and Wang, Q. (2016). Effect of surfactant amount on the morphology and magnetic properties of monodisperse $\mathrm{ZnFe}_{2} \mathrm{O}_{4}$ nanoparticles. Mater. Res. Bull. 75, 172-177. doi: 10.1016/j.materresbull.2015.11.052

Zheng, Y., Hunting, D. J., Ayotte, P., and Sanche, L. (2008). Radiosensitization of DNA by gold nanoparticles irradiated with high-energy electrons. Radiat. Res. 169, 19-27. doi: 10.1667/RR1080.1

Conflict of Interest Statement: The authors declare that the research was conducted in the absence of any commercial or financial relationships that could be construed as a potential conflict of interest.

Copyright (C) 2019 Gul, Khan, Rehman, Khan and Khan. This is an open-access article distributed under the terms of the Creative Commons Attribution License (CC $B Y)$. The use, distribution or reproduction in other forums is permitted, provided the original author(s) and the copyright owner(s) are credited and that the original publication in this journal is cited, in accordance with accepted academic practice. No use, distribution or reproduction is permitted which does not comply with these terms. 